\title{
ARTICLE
}

Translational Therapeutics

\section{Targeting eIF4F translation initiation complex with SBI-756 sensitises B lymphoma cells to venetoclax}

\author{
Lee-or Herzog ${ }^{1}$, Beth Walters ${ }^{2}$, Roberta Buono ${ }^{1}$, J. Scott Lee ${ }^{1,4}$, Sharmila Mallya ${ }^{1}$, Amos Fung ${ }^{1}$, Honyin Chiu ${ }^{1,5}$, Nancy Nguyen ${ }^{1}$, \\ Boyang $\mathrm{Li}^{1}$, Anthony B. Pinkerton ${ }^{3}$, Michael R. Jackson ${ }^{3}$, Robert J. Schneider ${ }^{2}$, Ze'ev A. Ronai (D) and David A. Fruman (D) ${ }^{3}$
}

BACKGROUND: The BCL2 inhibitor venetoclax has shown efficacy in several hematologic malignancies, with the greatest response rates in indolent blood cancers such as chronic lymphocytic leukaemia. There is a lower response rate to venetoclax monotherapy in diffuse large B-cell lymphoma (DLBCL).

METHODS: We tested inhibitors of cap-dependent mRNA translation for the ability to sensitise DLBCL and mantle cell lymphoma (MCL) cells to apoptosis by venetoclax. We compared the mTOR kinase inhibitor (TOR-KI) MLN0128 with SBI-756, a compound targeting eukaryotic translation initiation factor 4G1 (elF4G1), a scaffolding protein in the elF4F complex.

RESULTS: Treatment of DLBCL and MCL cells with SBI-756 synergised with venetoclax to induce apoptosis in vitro, and enhanced venetoclax efficacy in vivo. SBI-756 prevented elF4E-elF4G1 association and cap-dependent translation without affecting mTOR substrate phosphorylation. In TOR-KI-resistant DLBCL cells lacking elF4E binding protein-1, SBI-756 still sensitised to venetoclax. SBI756 selectively reduced translation of mRNAs encoding ribosomal proteins and translation factors, leading to a reduction in protein synthesis rates in sensitive cells. When normal lymphocytes were treated with SBI-756, only B cells had reduced viability, and this correlated with reduced protein synthesis.

CONCLUSIONS: Our data highlight a novel combination for treatment of aggressive lymphomas, and establishes its efficacy and selectivity using preclinical models.

British Journal of Cancer (2021) 124:1098-1109; https://doi.org/10.1038/s41416-020-01205-9

\section{BACKGROUND}

The mammalian target of rapamycin (mTOR) is a central regulator of cell growth and proliferation, as well as a target for therapeutics in cancer and other diseases. ${ }^{1}$ The two complexes that facilitate signal transduction in the mTOR pathway are mTORC1 and mTORC2. mTOR-activating mutations occur in diffuse large $B$ cell lymphoma (DLBCL), ${ }^{2}$ and elevated mTORC1 activity correlates with chemotherapy resistance and poor prognosis in pre-B acute lymphoblastic leukaemia (B-ALL). ${ }^{3}$

mTORC1 substrates include S6 kinases (S6Ks) and eukaryotic translation initiation factor 4E (elF4E)-binding proteins (4E-BPs). Phosphorylation of $4 \mathrm{E}-\mathrm{BP}$ releases its inhibition of elF4E. Upon release, elF4E binds the scaffolding protein eIF4G1 and the RNA helicase, elF4A, to form the elF4F protein translation initiation complex that binds to the $5^{\prime}$ cap of certain mRNAs and facilitates cap-dependent translation. ${ }^{4-6}$ Phosphorylation of 4E-BP1 correlates with high risk in B-ALL and chronic lymphocytic leukaemia, ${ }^{3,7}$ while mTOR inactivation impairs B-ALL survival., 8

Several mTORC1 inhibitors have been developed and investigated in the treatment of B-cell non-Hodgkin's lymphoma (NHL), yet each has caveats. Rapamycin and its analogues (rapalogs) are only partial inhibitors of mTORC 1 that do not effectively suppress 4E-BP1 phosphorylation. ${ }^{10}$ Second generation mTOR kinase inhibitors (TOR-KI) act as ATP-competitive inhibitors and fully inhibit both mTORC1 and mTORC2. ${ }^{11,12}$ One candidate TOR-KI studied in our lab, MLN0128/TAK-228, ${ }^{13}$ has entered a phase 2 clinical trial in B-ALL. TOR-KI have shown improved proapoptotic activity in preclinical studies ${ }^{11,12}$ yet their therapeutic potential is limited by several factors including toxicity ${ }_{16}^{14}$ adaptive survival signalling ${ }^{15}$ and mTOR resistance mutations. ${ }^{16}$

A promising alternative is to identify and target processes downstream of mTOR that are selectively required for cancer cell survival. One such process is cap-dependent mRNA translation controlled by the elF4F complex. ${ }^{4-6}$ Compared to normal cells, cancer cells are "addicted" to high levels of elF4F activity, ${ }^{4-6}$ as demonstrated using elF4E heterozygous mice, which were healthy yet resistant to Ras-driven tumorigenesis. ${ }^{17}$ Various malignant cells rely on cap-dependent translation of specific mRNAs encoding many oncogenes, cell cycle regulators and prosurvival factors ${ }^{4-6}$ including BCL2 family members (e.g. MCL- ${ }^{18}$ ). Hence, targeting cap-dependent translation downstream of mTOR could enhance efficacy of other proapoptotic therapies.

Currently available elF4F inhibitors have liabilities, including low potency, lack of selectivity or poor pharmacological properties. ${ }^{5}$ Here we use the novel small molecule inhibitor of elF4G1, named SBI-756, to target the elF4F translation initiation complex. ${ }^{19} \mathrm{SBI}$

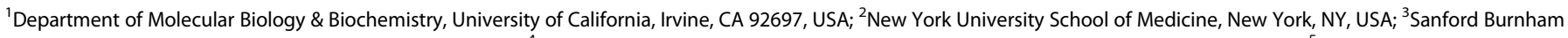

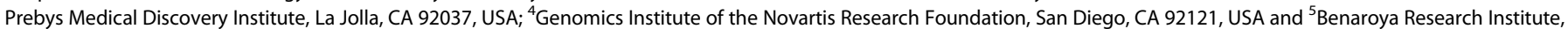
Seattle, WA 98101, USA

Correspondence: David A. Fruman (dfruman@uci.edu)

Received: 6 April 2020 Revised: 30 September 2020 Accepted: 20 November 2020

Published online: 14 December 2020 
756 is a small molecule that binds to elF4G1 and prevents its interaction with elF4E. ${ }^{19}$ In our previous study, SBI-756 inhibited melanoma in vitro and in vivo. ${ }^{19}$

Venetoclax is a small molecule $\mathrm{BH} 3$ mimetic drug that selectively binds BCL2 and inhibits its prosurvival function. ${ }^{20,21}$ Since initial FDA approval of venetoclax for treatment of chronic lymphocytic leukaemia (CLL) patients with $17 \mathrm{p}$ chromosomal deletion, ${ }^{22}$ additional combination regimens have been approved. ${ }^{23,24}$ Novel combinations are needed to improve responses in $\mathrm{NHL}$, where single agent venetoclax has limited activity. ${ }^{25}$ Here we tested the efficacy of SBI-0640756 (SBI-756 hereafter) in NHL cell lines, alone and in combination with venetoclax. We find that SBI-756 synergises with venetoclax in DLBCL and mantle cell lymphoma $(\mathrm{MCL})$ cells in vitro, and promotes tumour regression in vivo. SBI756 at nanomolar concentrations disrupts the elF4G1:elF4E interaction in cells, reprogramming mRNA translation and sensitising to apoptosis. Lymphoma cells with natural or engineered loss of 4E-BP1 were resistant to TOR-Kls yet retained sensitivity to SBI756. Mechanistic experiments showed that SBI-756 had a selective effect on translation efficiency of components of the translation machinery, leading to reduced protein synthesis rates. These results identify disruption of elF4F assembly as a promising approach to enhance venetoclax efficacy in NHL.

\section{METHODS}

Duolink proximity ligation assay (PLA)

We performed PLA as described before. ${ }^{26}$ Briefly: $2 \times 10 \mathrm{e} 6$ cells were treated for $4 \mathrm{~h}$ as indicated. Cells were washed with $1 \times$ phosphate buffered saline (PBS) (Corning, NY) and fixed with $4 \%$ paraformaldehyde (Thermo Fisher Scientific). CometSlides (Trevigen, Gaithersburg, MD) were coated with Poly-L-Lysine $0.1 \%$ solution (Sigma-Aldrich (SA), St. Louis, MO), and cells were allowed to adhere. We followed the protocol of Duolink PLA; ${ }^{27}$ briefly: Cells were blocked using Duolink blocking solution, followed by probing with primary antibodies for elF4G1 (Cell signaling Technologies, Danvers, MA, Cat. \#2858, 1:200 dilution) and elF4E (BD Biosciences, San Diego, CA, Cat. \#610269, $2.5 \mu \mathrm{g} / \mathrm{ml}$ final). Next, cells were incubated with Duolink In Situ PLA Probe Anti-Rabbit PLUS (Cat. \# DUO92002) and Duolink In Situ PLA Probe Anti-Mouse (Cat. \# DUO92004) and allowed to ligate using ligation mix. Next, amplification and washes were performed as instructed and the slides were mounted using media containing DAPI. Slides were imaged using Leica TCS SP8 confocal microscope. Signal obtained was quantified using ImageJ software, and normalised to the number of cells per field (using DAPI nuclei staining). Images shown indicate the signal (Orange Duolink ${ }^{\mathrm{TM}}$ ) and nuclei for each field imaged, while graphs presented indicate ratio values of signal per cell in each field imaged.

Mice strain and compounds administration in vivo

Thirty-two NOD scid gamma (NSG) healthy immunodeficient mice (Jackson Laboratories, Bar Harbor, ME) were used for in vivo experiments ( 8 weeks old, 23 gram in average) after 7 days acclimation in animal facility. Animal studies were approved by the Institutional Animal Care and Use Committee at UC Irvine. Female NSG mice were injected subcutaneously (s.c.) with $1 \times$ $10 \mathrm{e} 6 \mathrm{OCl}-\mathrm{LY} 1$ cells/mouse. We anesthetised the mice $(100 \mathrm{mg} / \mathrm{kg}$ ketamine- $10 \mathrm{mg} / \mathrm{kg}$ xylazine) and cells were injected in total volume of $200 \mu \mathrm{l}$ along with Matrigel (Corning) for providing a supportive environment for tumour development. Once tumour size reached $110 \mathrm{~mm}^{3}$ volume, mice were randomised into treatment groups $(n=8)$ and treated daily (non-blinded way) for 5 days. Each mouse body weight was examined throughout the trial to identify potential toxicity or changes in dosing parameters. Also, tumour sizes were monitored daily and recorded. All mice were monitored for clinical signs of pain or distress during the procedures and daily during tumour measurements; no clinical signs were observed. At the end of five days of dosing, each mouse was weighed, sacrificed (according to IACUC guidelines, using $\mathrm{CO}_{2}$ inhalation followed by cervical dislocation) and tumours were excised for analysis. Analysis of tumours included tumour size, weight and preparation of single-cell suspension without exclusion of data points. Cells extracted were fixed using 4\% PFA and used for intracellular staining as well as PLA.

\section{Polysome profiling}

Cells were grown to $\sim 70 \%$ confluence. Cycloheximide $(0.1 \mathrm{mg} / \mathrm{mL}$ final concentration) was added to the medium for $5 \mathrm{~min}$ at $37^{\circ} \mathrm{C}$ to arrest the ribosomes. The cells were washed twice with PBS containing $0.1 \mathrm{mg} / \mathrm{mL}$ cycloheximide, and then pelleted. The supernatant was removed, and the pellet was flash frozen. Cell pellets were lysed for $10 \mathrm{~min}$ on ice with $400 \mu \mathrm{L}$ polysome extraction buffer (15 mM Tris-Cl, pH7.4, $15 \mathrm{mM} \mathrm{MgCl} 2,0.3 \mathrm{M} \mathrm{NaCl}, 0.1 \mathrm{mg} / \mathrm{mL}$ cycloheximide, $0.1 \mathrm{mg} / \mathrm{mL}$ heparin, $1 \%$ Triton $\mathrm{X}-100)$. The lysates were cleared by centrifugation at $13,200 \times g$ for $10 \mathrm{~min}$. Equal RNA concentrations were layered onto $20-50 \%$ sucrose gradients. Gradients were sedimented at $151,263 \times g$ for $103 \mathrm{~min}$ in a SW55 Ti rotor at $4{ }^{\circ} \mathrm{C}$. An ISCO UA- 6 (Teledyne, Thousand Oaks, CA) fraction collection system was used to collect 12 fractions, which were immediately mixed with 1 volume of $8 \mathrm{M}$ guanidine $\mathrm{HCl}$. RNA was precipitated from polysome fractions by ethanol precipitation and dissolved in $20 \mu \mathrm{L}$ of $\mathrm{H}_{2} \mathrm{O}$. Briefly, fractions were vortexed for $20 \mathrm{~s}$. $600 \mu \mathrm{L}$ of $100 \%$ ethanol was added, and fraction was vortexed again. Fractions were incubated overnight at $-20^{\circ} \mathrm{C}$ to allow for complete RNA precipitation. Fractions were centrifuged at $13,200 \mathrm{rpm}$ for 30 $\min$ at $4{ }^{\circ} \mathrm{C}$. The RNA pellet was washed with $75 \%$ ethanol. The pellet was resuspended in $400 \mu \mathrm{L} 1 \times$ Tris-EDTA ( $\mathrm{pH}$ 8.0). 0.1 volumes of $3 \mathrm{M}$ $\mathrm{NaOAc}$ (pH 5.3) and 2.5 volumes $100 \%$ ethanol were added, and fractions were incubated at $-20^{\circ} \mathrm{C}$ to precipitate RNA. Fractions were centrifuged at $13,200 \mathrm{rpm}$ for $30 \mathrm{~min}$ at $4{ }^{\circ} \mathrm{C}$. The RNA pellet was washed with $75 \%$ ethanol. RNA was resuspended in $20 \mu \mathrm{L} \mathrm{H}_{2} \mathrm{O}$. Total RNA samples were isolated from cell lysates using Trizol per the manufacturer's instructions.

RNA-seq and analysis

Fractions containing four or more ribosomes (considered welltranslated) were pooled and RNA quality was measured by a Bioanalyzer (Agilent Technologies). RNA-seq was carried out by the New York University School of Medicine Genome Technology Core using the Illumina HiSeq 4000 single read. To examine differences in transcription and translation, total mRNA and polysome mRNA were quantile-normalised separately. Statistical analysis was performed using RIVET. ${ }^{28} \mathrm{GO}$ analysis was performed using the DAVID online tool.

\section{Statistical analysis}

The number " $\mathrm{n}$ " of biological replicates for each experiment is indicated in the figure legends. Two-way ANOVA for multiple comparisons was performed where indicated while considering sample independence, variance equality and normality. ANOVA analysis while adjusting for multiple comparisons was performed for the in vivo experiment described to test for tumour growth. Student $t$-tests were applied to population means assuming equal variance (standard deviations within two-fold). The use of one- versus twosample tests, and paired versus unpaired comparisons, was justified by the experimental design as indicated in the Figure Legends.

Additional standard and published methods are provided in the Supplementary Materials.

\section{RESULTS}

Constitutively active 4E-BP1 mutant sensitises DLBCL cells to venetoclax, similar to TOR-KI treatment

mTOR inhibitors enhance killing of DLBCL cells by $\mathrm{BH} 3$ mimetics, such as venetoclax (ABT-199), ABT-263 or ABT-737. ${ }^{29}$ To evaluate 
the role of the $4 \mathrm{E}-\mathrm{BP} / \mathrm{elF} 4 \mathrm{E}$ axis in this sensitisation, we used a doxycycline (DOX)-inducible system to express wild-type 4E-BP1 or a constitutively active form in which all five serine/threonine phosphorylation sites were changed into alanine (5A mutant). Since 4E-BP1-5A cannot be phosphorylated by mTORC1, expression of this mutant prevents elF4E from associating with elF4G1 and other proteins to form the elF4F complex. ${ }^{30}$ We generated OCI-LY1 DLBCL cells expressing the reverse tetracycline transactivator (rtTA) protein and either empty vector (EV), WT 4E-BP1 or 4EBP1 mutant (5A). Addition of DOX induced expression of the mutant protein after $16 \mathrm{~h}$ (Fig. S1a). Next, we treated cells ( \pm DOX) for $48 \mathrm{~h}$ with a range of venetoclax concentrations in combination with either vehicle (DMSO), or TOR-KI (MLN0128 $100 \mathrm{nM})$. As expected, TOR-KI treatment sensitised to venetoclax as shown by reduced IC50 values (Fig. S1b). Notably, OCl-LY1 cells expressing the active 4E-BP1 (5A) and treated with vehicle (lane 5, Fig. S1a) were as sensitive to venetoclax as control cells (WT or EV) treated with TOR-KI (lanes 2 and 4 Fig. S1b). TOR-KI further increased sensitisation to venetoclax in cells expressing 4E-BP1 MUT. A similar sensitisation was observed in OCl-LY1 cells expressing 4EBP1 5A and treated with navitoclax (ABT-263) - an inhibitor of $B C L 2, B C L 2 L 1$ (BCL-xL), and BCL-W (Fig. S1C, d). In summary, the ability of the 4E-BP1 mutant to phenocopy the effect of TOR-KI demonstrates that targeting the 4E-BP1/elF4E arm of mTORC1 signalling is a promising approach for sensitisation of DLBCL cells to venetoclax treatment.

SBI-756 prevents elF4E:elF4G1 association and reduces capdependent translation in lymphoma cells

Next, we took a chemical approach to disrupting elF4F. Previously, we showed that the cell-permeable compound SBI-756 binds to elF4G1 and disrupts formation of the mRNA cap-binding complex in melanoma cells and in fibroblasts. ${ }^{19}$ To assess the effect of SBI756 on elF4F formation in lymphoma cells, we used a proximity ligation assay (PLA) to quantitate the interaction of elF4E and elF4G1 in situ. As expected, treatment of OCI-LY1 cells with the TOR-KI compound MLN0128 suppressed elF4E:elF4G1 association whereas rapamycin, a weak inhibitor of 4E-BP1 phosphorylation, ${ }^{10,30}$ had no significant effect (Fig. 1a, b). SBI756 reduced elF4E:elF4G1 interaction in a dose-dependent manner (Fig. 1a, b). Similar results were observed in OCI-LY8 cells (Fig. S2a, b). Quantification of elF4E:elF4G1 interaction indicated a significant reduction by $500 \mathrm{nM} \mathrm{SBI-756} \mathrm{in} \mathrm{OCl-LY1} \mathrm{(76 \% ,} \mathrm{Fig.} \mathrm{1b)}$ and $250 \mathrm{nM}$ in OCl-LY8 (83\%, Fig. S2b).

We used dual-luciferase reporter assays to test the ability of TOR-KI and SBI-756 to reduce cap-dependent and IRES-dependent translation. Following $16 \mathrm{~h}$ of treatment of OCI-LY1 and the MCL cell line Mino1, SBI-756 in the range of $100-500 \mathrm{nM}$ selectively reduced cap-dependent luciferase expression (Fig. 1C). Similar results were observed in two additional DLBCL lines (OCI-LY8, SUDHL6) and in the Maver1 MCL line (Fig. S2c). Likewise, MLN0128 significantly reduced accumulation of cap-dependent luciferase (Figs. 1c and S2).

\section{SBI-756 does not change mTOR substrate phosphorylation}

A potential advantage of selective elF4F targeting is that this approach should preserve activity of $\mathrm{mTOR}$, reducing on-target toxicities associated with mTOR inhibition. Compared to the TOR$\mathrm{KI}$ compound Torin-1, SBI-756 (1 $\mu \mathrm{M}$ or lower concentration) did not inhibit phosphorylation of mTORC1 or mTORC2 substrates in melanoma cells. ${ }^{19}$ To test whether SBI-756 alters mTOR activity in lymphoma cells, we measured mTORC1 and mTORC2 substrate phosphorylation. As expected, MLN0128 significantly reduced phosphorylation of both mTORC1 (p-S6, p-4E-BP1) and mTORC2 (AKT) substrates, whereas rapamycin reduced only p-S6 (Fig. S3a, b). In contrast, treatment with SBI-756 did not alter phosphorylation of any mTOR substrates tested, indicating that the mTOR signalling pathway was not altered by SBI-756 treatment (Fig. S3a, b). Similar results were obtained in other DLBCL cell lines (Fig. S3C, d). These results support the conclusion that SBI-756 directly disrupts the elF4F complex without altering activity of mTORC1 or mTORC2.

SBI-756 synergises with venetoclax to increase apoptosis To test the ability of SBI-756 to promote apoptosis and sensitise lymphoma cells to venetoclax, we evaluated seven GCB-DLBCL and five MCL cell lines (Figs. 1d, e and S4). We treated the cells with titrated concentrations of venetoclax as a single agent, or in combination with either MLN0128 or SBI-756 (Figs. 1d, e and S4a, b) and performed viability assays. Eight of the cell lines tested had reduced viability following $48 \mathrm{~h}$ treatment with venetoclax as a single agent. Ten cell lines showed reduced viability following SBI756 treatment as a single agent. In five of the SBI-756-sensitive DLBCL lines (OCI-LY1, OCI-LY8, OCI-LY18, SU-DHL-4, SU-DHL-6) and four of the MCL lines (Mino, Jeko1, MAVER-1, CCMCL-1), the combination of SBI-756 and venetoclax caused more cell death than individual agents (Figs. 1d, e and S4). In comparison, MLN0128 only sensitised to venetoclax in one cell line (OCI-LY1) (Fig. 1d) despite effectively suppressing mTOR signalling outputs in other cell lines such as OCI-LY8 (Fig. S3a, c). Supporting an apoptotic mechanism, the combination of SBI-756 with venetoclax induced caspase-dependent death, as demonstrated by rescue of viability in cells co-treated with the pan-caspase inhibitor QVD$\mathrm{OPH}$ (Fig. S5a). Moreover, venetoclax treatment with or without SBI-756 led to cleavage of caspase-3 and PARP (Fig. S5b). Treatment with SBI-756 alone did not induce cleavage of caspase- 3 or PARP (Fig. S5b).

Next, we chose sensitive $D L B C L$ and $M C L$ cells to further evaluate synergy between venetoclax and SBI-756 (Figs. 1f, $\mathrm{g}$ and S4c). We measured viability in cells treated for $48 \mathrm{~h}$ with fixed ratios of venetoclax and SBI-756 and assessed synergy using the Chou-Talalay method. ${ }^{31}$ Indeed, SBI-756 synergised with venetoclax (combination index $<1$ ) in both OCl-LY1 (DLBCL) and Mino1 (MCL) cells (Fig. 1f, g). Furthermore, SBI-756 was found to synergise with venetoclax in five more cell lines tested (Fig. S4c).

SBI-756 did not reduce viability or sensitise to venetoclax in the OCI-LY7 DLBCL line and had minimal effect in a subline of OCI-LY1 cells that we selected for resistance to SBI-756 (Fig. S4a). In both these cell lines, SBI-756 treatment did not prevent the elF4E: elF4G1 interaction measured by PLA (Fig. S4d).

Lymphoma cells lacking 4E-BP1 are resistant to TOR-KI yet remain sensitive to SBI-756

Many cancer cells exhibit a reduction of $4 \mathrm{E}-\mathrm{BP}$ expression ${ }^{32,33}$ or increase in elF4E expression, ${ }^{34,35}$ enabling cap-dependent translation even following mTORC1 inhibition. Indeed, the elF4E/4E-BP ratio can predict efficacy of mTOR targeted therapies. ${ }^{36}$ Previously we reported that SBI-756 can fully suppress proliferation in $4 \mathrm{E}-$ $\mathrm{BP} 1 / 4 \mathrm{E}-\mathrm{BP} 2$ double knockout fibroblasts that are partially resistant to the TOR-KI compound Torin-1. ${ }^{19}$ To determine whether SBI-756induced DLBCL death is $4 \mathrm{E}-\mathrm{BP}$-dependent, we used CRISPR/Cas9 genome editing to generate clones of OCI-LY1 cells lacking 4E-BP1 (Fig. S6). We compared these 4E-BP1 knockout (KO) clones to OClLY1 cells expressing Cas9 and empty sgRNA vector (EV) in viability assays, using a range of venetoclax concentrations without or with MLN0128 or SBI-756. As in parental cells, $10 \mathrm{nM}$ venetoclax caused $\sim 10 \%$ death in the EV and 4E-BP1 KO lines (Fig. 2a-d); higher concentrations of venetoclax caused more death. MLN0128 and SBI-756 sensitised to venetoclax in EV cells (Figs. 2a, b) as in parental OCI-LY1 (Fig. 1d). Notably, OCI-LY1 cells lacking 4E-BP1 were completely resistant to MLN0128 yet remained sensitive to SBI-756 alone or in combination with venetoclax (Figs. 2c, $d$ and S6). Similarly, SBI-756 reduced elF4E:elF4G1 interaction among all cells, whereas treatment with MLN0128 reduced interaction only in control cells containing 4E-BP1 (Figs. 2e, f). Our findings indicate that in cells lacking 4E-BP1 expression, SBI-756 retains its effect 

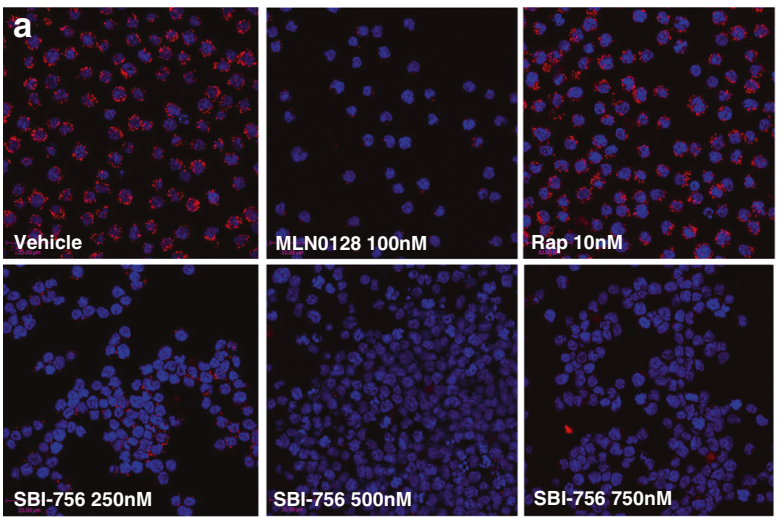

b

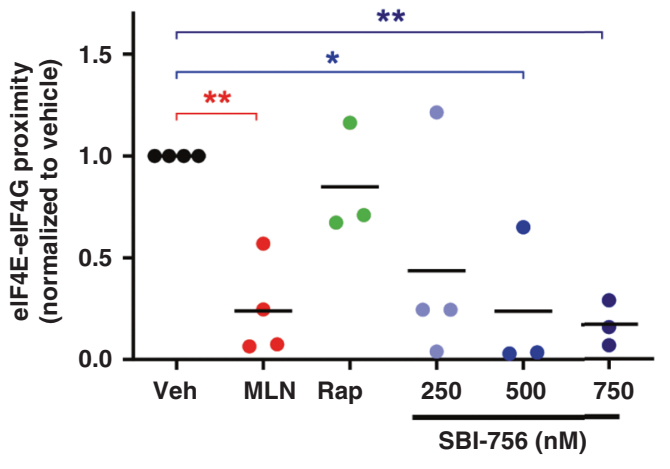

C
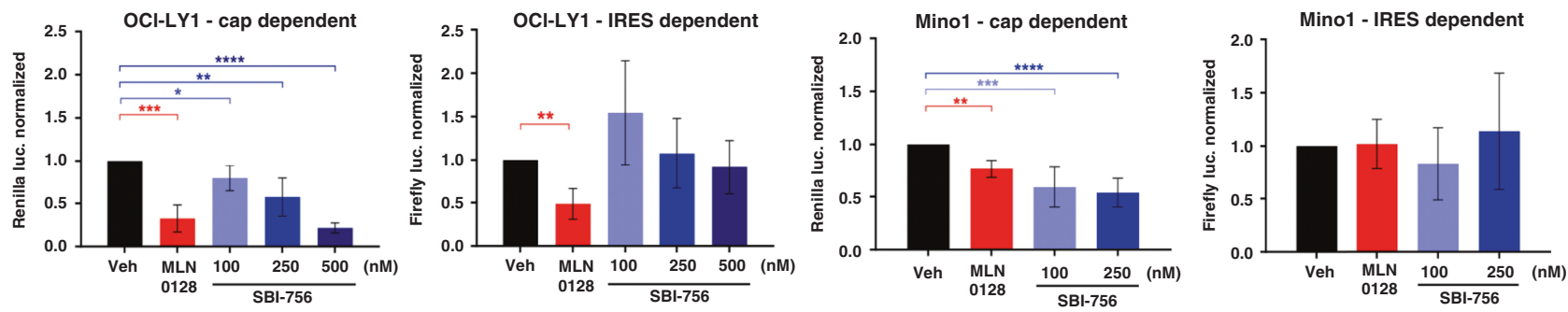

d

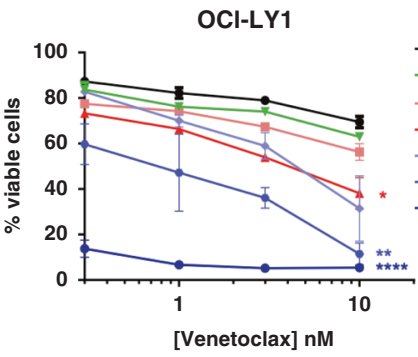

$\rightarrow$ Vehicle

* Rapamycin $10 \mathrm{nM}$

- MLN0128 30nM

- MLN0128 100nM

$\rightarrow$ SBl-756 100nM

- SBI-756 250nM

- SBI-756 500nM

e

Mino1

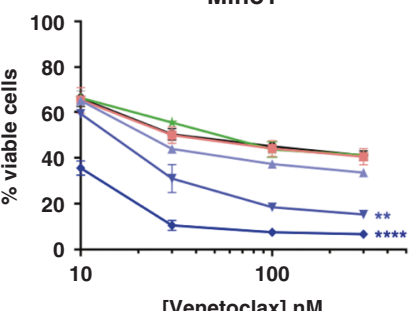

f

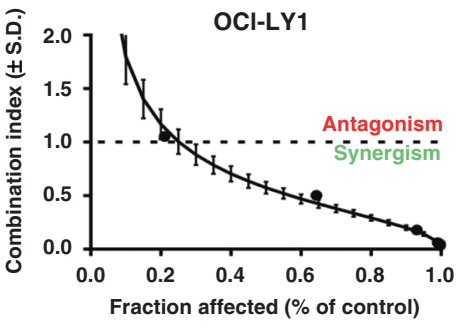

g

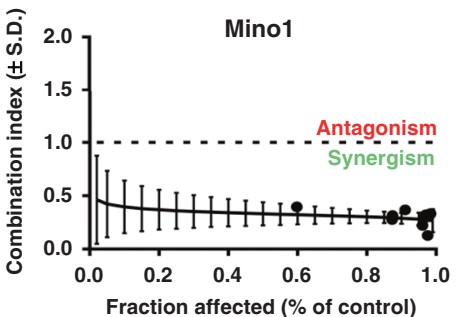

Fig. $1 \mathrm{SBI}-756$ prevents elF4E-elF4G interaction and cap-dependent translation. a Cells were tested for elF4E:elF4G1 association via Proximity Ligation Assay (PLA). OCI-LY1 DLBCL cells were treated for $4 \mathrm{~h}$ with either vehicle (DMSO), MLN0128 $100 \mathrm{nM}$, Rapamycin $10 \mathrm{nM}$ or increasing concentrations of SBI-756 $(250-750 \mathrm{nM})$. Scale bar $=33 \mu \mathrm{m}$. Representative images of at least three fields are shown. b Quantification of elF4E:elF4G1 interaction for each treatment. The signal indicating elF4E:elF4G interaction was measured from the entire field for each treatment (single channels acquired) and was normalised to the number of cells imaged (DAPI staining indicating cells/ image). Relative ratios are graphed. ${ }^{*} p<0.05 ;{ }^{* *} p<0.01 . n=3$ or 4 , as indicated. Paired one-sample $t$-test. c OCI-LY1 or Mino1 cells were electroporated to introduce the dual-luciferase reporter in which $5^{\prime}$ cap-dependent untranslated region (5'-UTR) was conjoined to a Renilla (Renilla reniformis) luciferase reporter, while the Internal Ribosomal Entry Site (IRES) was conjoined to a firefly (Photinus pyralis) luciferase reporter. Cells were treated for $16 \mathrm{~h}$ with vehicle (DMSO), MLN0128 $100 \mathrm{nM}$, or increasing concentrations of SBI-756 (250-750 nM). Both Renilla luciferase (cap-dependent translation) and firefly luciferase (IRES dependent translation) signals were measured and each was normalized to vehicle contol. ${ }^{*} p<0.05,{ }^{* *} p<0.01,{ }^{* * *} p<0.005$. One-sample $t$-test vs. DMSO control. $n=3$. Viability of $\mathbf{d}$ OCI-LY 1 and e Mino 1 cells treated for $48 \mathrm{~h}$ with increasing venetoclax concentrations in combination with vehicle (DMSO) control or various inhibitors as indicated. Viability was assessed using Annexin V and PI staining. ${ }^{*} p<0.05 ;{ }^{* *} p<0.01 ;{ }^{* * * *} p<0.001$. We performed independent $t$-tests (unpaired $t$-tests) and compared each treatment group to vehicle treated group. We also performed an adjustment for multiple comparisons for each $t$-test performed. We calculated IC50 values for each cell line tested based of the viability assays performed: $\mathbf{f}$ OCI-LY1 IC50s-venetoclax $23.6 \mathrm{nM}$, SBI756209.7 nM; g Mino1 IC50s-venetoclax 749.9 nM, SBI-756 $340.3 \mathrm{nM}$. Isobologram plots were graphed based on Chou-Talalay method for synergy calculation (combination index) ${ }^{11}$ using median effect method for cell lines treated for $48 \mathrm{~h}$ with combinations of SBI-756 and venetoclax at fixed ratios. 

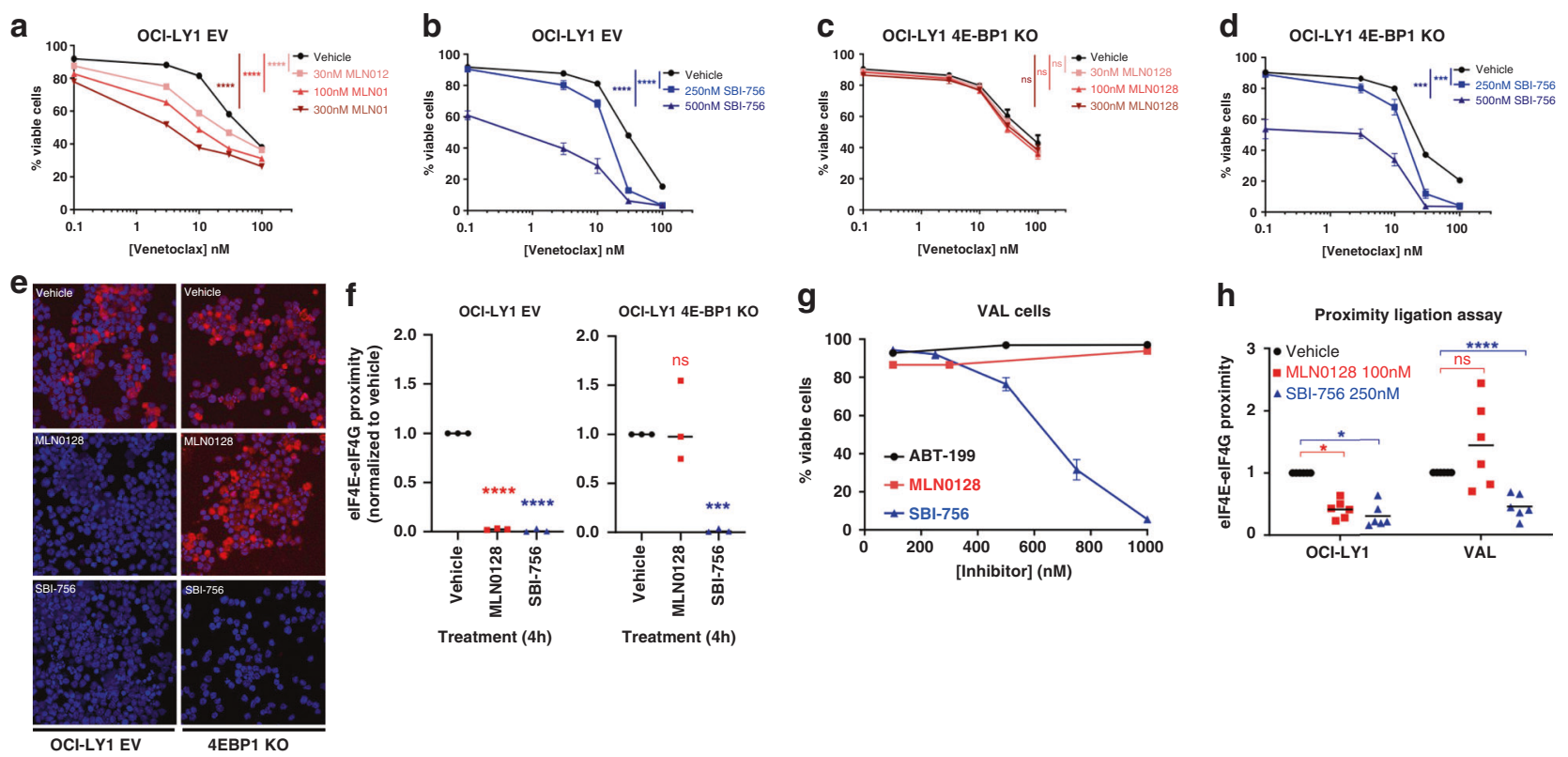

Fig. 2 Lymphoma cell lacking 4E-BP1 are resistant to TOR-KI yet are sensitive to SBI-756 treatment. OCI-LY1 cells stably expressing Cas9 were transfected with guide RNAs. Clones were isolated that carried an empty vector (a, b, e); or sgRNAs specific for 4E-BP1 (4E-BP1 KO) (c, d, f). Parental OCI-LY1 cells gave comparable results to EV transfected OCI-LY1 (data not shown). a-d. Cells were treated for $48 \mathrm{~h}$ with titrated amounts of venetoclax without (vehicle) or with MLN0128 (a, c) or SBI-756 (b, d). Viability was assessed using annexin V and PI staining. $n=4$. ${ }^{*} p<0.05,{ }^{* * *} p<0.01,{ }^{* * *} p<0.005$, ns not significant. Statistics were done using Two-way ANOVA. e, f PLA comparing parental OCI-LY1 to 4EBP1 KO cells after 4 hours treatment. Five fields were imaged and quantified by a blinded observer (e). Data are plotted for individual experiments with the means of each group indicated by a horizontal line (f). $n=3 .{ }^{*} p<0.05,{ }^{* *} p<0.01,{ }^{* * *} p<0.005$, ${ }^{* * * *} p<0.001$, ns not significant. Paired one-sample $t$-test vs. control. g Viability assay of VAL cells (naturally lacking $4 \mathrm{E}-\mathrm{BP} 1^{6}$ ) following $48 \mathrm{~h}$ of treatment with venetoclax, MLN0128 or SBI-756 (all within 100-1000 nM range). $\mathbf{h}$ PLA comparing OCI-LY1 to VAL cells (naturally lack 4E-BP1 ${ }^{6}$ ) following $4 \mathrm{~h}$ of treatment. Fields imaged and quantified by a blinded observer. Data are plotted for individual experiments with the means of each group indicated by a horizontal line. $n=3 .{ }^{*} p<0.05,{ }^{* *} p<0.01,{ }^{* * *} p<0.005,{ }^{* * *} p<0.001$, ns not significant. Paired one-sample $t$-test vs. control.

and prevents elF4F formation, thus sensitising those cells to BCL2 inhibition.

To further support this conclusion, we used VAL cells, a DLBCL line lacking $4 \mathrm{E}-\mathrm{BP} 1^{32}$ (Fig. S3d). Consistent with previous observations, ${ }^{32}$ MLN0128 at concentrations up to $3 \mu \mathrm{M}$ did not affect VAL cell viability (Fig. $2 \mathrm{~g}$ ) or elF4E:elF4G interaction (Fig. 2h). In contrast, SBI-756 reduced viability of VAL cells (Fig. $2 \mathrm{~g}$ ) and disrupted the elF4E:elF4G interaction (Fig. 2h). VAL cells were completely insensitive to venetoclax, with or without SBI-756. Nevertheless, these data confirm that prevention of elF4F complex formation is achievable using SBI-756, even among cells lacking 4E-BP1 (thus insensitive to TOR-KI).

SBI-756 is effective and well tolerated in vivo

We assessed whether sensitisation of DLBCL to venetoclax treatment by cotargeting elF4F could be recapitulated in vivo. We injected NSG mice with OCI-LY1 (s.c.) and once palpable tumours were established, treated with vehicle, venetoclax, SBI756 or their combination for 5 consecutive days (Fig. 3a). There was no significant change in body weight among the different groups (Fig. S7a), indicating that the treatments were well tolerated. Both venetoclax and SBI-756 significantly slowed tumour growth when administered as single agents (Figs. 3b, S7b, c). Notably, venetoclax and SBI-756 combination caused tumour regression and significantly reduced tumour volume (7/7 mice) when compared to SBI-756 (1/8 mice) or venetoclax ( $2 / 8$ mice) as single agents or vehicle alone ( $0 / 8$ mice). Together these results indicate that a synergistic relationship between venetoclax and SBI-756 occurs not only in vitro but also in vivo.

SBI-756 has a pharmacodynamic effect in vivo To assess whether SBI-756 treatment prevents elF4E:elF4G1 interaction in vivo, lymphoma tumours excised from euthanised mice were dissociated into single cells and subjected to PLA. Analysis of the samples obtained showed a reduction in elF4E: elF4G1 interaction among tumours treated with SBI-756 as a single agent or in combination with venetoclax, compared to vehicle or venetoclax alone (Fig. 3c, d). Additionally, we performed intracellular staining to measure phosphorylation levels of mTOR substrates, S6 kinase and 4E-BP1, among the samples extracted from the tumours to test for alteration in mTOR kinase activity. No significant changes were observed in MTOR substrate phosphorylation in mice treated with SBI-756 and/or venetoclax in vivo (Fig. S7d, e). These results suggest that SBI-756 potentiates venetoclax efficacy in vivo by preventing elF4E:elF4G1 interaction without affecting mTOR activity.

SBI-756 has both direct and indirect effects on mRNA translation Chemical inhibition of mTORC1 or elF4F in cancer cells selectively suppresses translation of mRNAs with specific features in the $5^{\prime}$ untranslated region (UTR). ${ }^{37}$ These elF4F-sensitive mRNAs include several that encode prosurvival proteins, including $M C L-1, B C L-x L$ and survivin. ${ }^{18}$ To determine whether SBI-756 affects expression of these factors in DLBCL cells, we measured expression of candidate proteins by western blot. In cells growing asynchronously, 4-h treatment with MLN0128 or SBI-756 did not change expression of these candidate proteins (data not shown). In a previous study we found that serum starvation of DLBCL cells, followed by readdition of serum without or with mTOR inhibitors, revealed consistent changes in protein expression. ${ }^{32}$ Taking this approach, we observed modest and variably reduced expression ( 2-fold) of MCL-1, BCL-xL and survivin among MLN0128 and SBI-756 treated cells (Fig. S8a, b). Expression of elF4E or elF4G1 were also reduced following SBI-756 or MLN0128 treatment (Fig. S8a, b). For each of these targets (MCL-1, BCL-XL, survivin, elF4E or elF4G1), the abundance of mRNA was not significantly changed in cells treated 


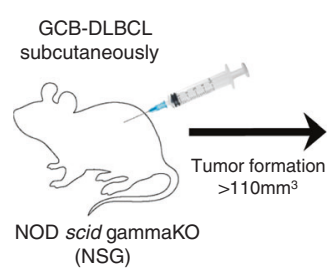

C
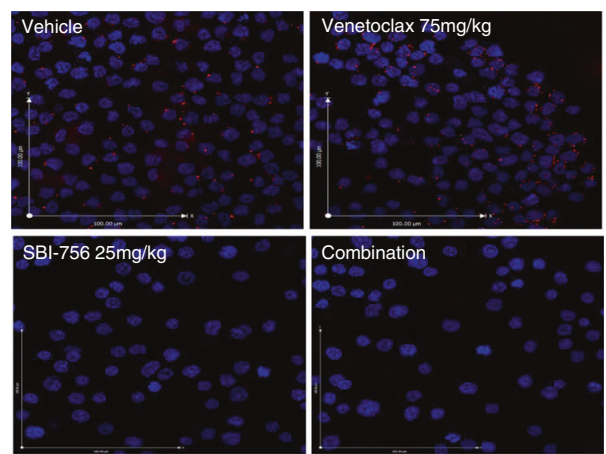

b

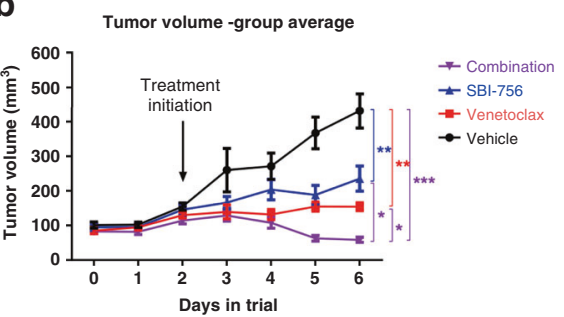

d

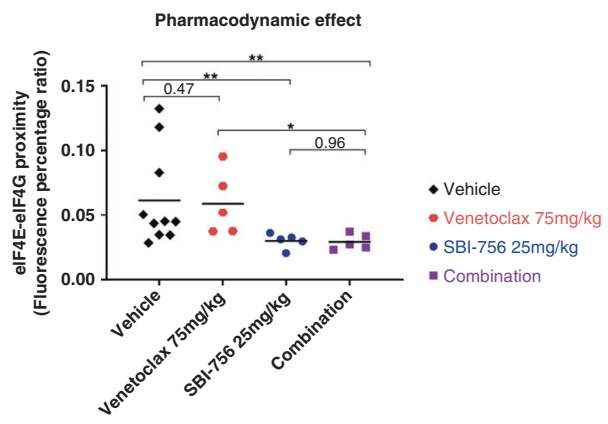

Fig. $3 \mathrm{SBI-756}$ sensitises to venetoclax treatment in vivo. a. NOD-scid-IL2-Rgamma-/- (NSG) immunodeficient mice were injected with 1x10e7 OCI-LY1 cells s.C. (7-8 mice per group). Once palpable tumours were established $\left(>110 \mathrm{~mm}^{3}\right)$, mice were treated with $0.1 \%$ DMSO vehicle (i.p. and p.o.), SBI-756 $25 \mathrm{mg} / \mathrm{kg}$ (i.p.), venetoclax $75 \mathrm{mg} / \mathrm{kg}$ (p.o.) or combination (i.p. and p.o.) for five consecutive days (Fig. 3). The tumour weight, single-cell extractions and pharmacodynamics were monitored on the day of sacrifice, while mouse body weight and tumour volume were monitored throughout the trial. bTumour volume was calculated each day using the formula: $v=4 / 3 \pi r_{1} r_{2} r_{3}$ and presented as mean \pm SEM. ${ }^{*} p<0.05,{ }^{* *} p<0.01,{ }^{* *} p<0.005,{ }^{* * *} p<0.001$, ANOVA, $p$ value has been adjusted for multiple comparisons (using Tukey's adjustment). c elF4E:elF4G1 association measured by PLA assay on single cells isolated from tumours. SBI-756 treatment (alone/combination) reduced association of elF4E:elF4G1. scale bar $=100 \mu \mathrm{m}$. d Quantification of elF4E:elF4G1 interaction for each treatment group. Each point represents one mouse in the group that was treated for 5 consecutive days and euthanised $4 \mathrm{~h}$ after the last dose. The signal indicating elF4E: elF4G interaction was measured from the entire field for each treatment (single channels acquired) and was normalised to the number of cells imaged (DAPI staining indicating cells/image). Relative ratios are graphed. Data are plotted for individual experiments with the means of each group indicated by a horizontal line. ${ }^{*} p<0.05 ;{ }^{* *} p<0.01$, ANOVA, $p$ value adjusted for multiple comparisons.

with SBI-756 or MLN0128 (with the exception of survivin transcripts elevated in cells treated with $500 \mathrm{nM} \mathrm{SBI-756)} \mathrm{(Fig.} \mathrm{S8c).}$

To gain a broad, unbiased view of how SBI-756 affects mRNA translation efficiency, we treated OCI-LY1 cells with vehicle (DMSO) or SBI-756 (250 nM) for $4 \mathrm{~h}$, and isolated RNA from heavy and light polysome fractions, as well as total cellular RNA. The 4- $h$ treatment did not cause detectable changes in RNA distribution from heavy to light polysomes (Fig. 4a) and did not change rates of overall protein synthesis (Fig. 4b). However, comparison of mRNAs associated with heavy polysomes to total mRNAs showed that SBI-756 selectively changed the translation efficiency of 538 mRNAs; 13 showed differences in both translation and transcription (Fig. 4c, d, Supp. Table 1). Only 24 genes showed changes in transcription alone (Fig. 4c, d), supporting the conclusion that SBI756 is an on-target and selective inhibitor of mRNA translation.

Of the 538 mRNAs with selective change in translation, the majority (385) had reduced translation efficiency (Fig. 4c) (Supp. Table 1). Gene ontology (GO) analysis showed a highly significant enrichment for genes involved in mRNA translation. The most enriched biological processes for the downregulated genes (Fig. $4 \mathrm{e}$ top) include translation initiation, translation, rRNA processing and ribosomal small subunit assembly. Likewise, top molecular functions associated with the downregulated genes include structural constituent of the ribosome, RNA binding and poly $(A)$ RNA binding (Fig. 4f). Among the translationally downregulated biological processes were negative regulators of apoptosis (Fig. 4e). This family contained 10 genes (Supplementary Table 2) yet did not include the candidates mentioned above (MCL-1, BCL$\mathrm{XL}$, survivin). Among the translationally upregulated mRNAs, only one was found to contain an IRES motif (TP53).
The dramatic reduction in translation of mRNAs encoding ribosomal proteins and regulators at $4 \mathrm{~h}$ suggested that SBI-756 might indirectly reduce overall translation efficiency over time. Indeed, 16-h treatment with SBI-756 reduced rates of total protein synthesis in parental OCI-LY1 cells (Fig. 5a) but not in the SBI-756resistant subline of OCI-LY1 cells (Fig. 5b). MLN0128 or SBI-756 treatment did not reduce protein synthesis in the OCl-LY7 cell line (Fig. 5c), in which these agents did not have cytotoxic activity (Fig. S4a). Nevertheless, SBI-756 did reduce protein synthesis in OCI-LY8 and SU-DHL-6 cell lines (Fig. 5d, e). This reduced protein synthesis could account for the sensitisation to venetoclax observed among these cells (Fig. S4a). Considering that SBI-756 reduced protein synthesis in OCl-LY1 cells at $16 \mathrm{~h}$ but not $4 \mathrm{~h}$, we assessed cell survival at these timepoints as well as $24 \mathrm{~h}$ and $48 \mathrm{~h}$. Sensitisation to venetoclax cytotoxicity was first evident $16 \mathrm{~h}$ following SBI-756 treatment (Fig. 5f), and was significantly greater than combination with TOR-KI.

SBI-756 is not cytotoxic to human CD4+T cells, CD8+T cells, NK cells or monocytes

Lastly, we evaluated whether SBI-756 cytotoxic effects are selective for transformed lymphoma cells versus normal lymphocytes. We cultured PBMCs from healthy donors for $48 \mathrm{~h}$ with SBI756 or MLN0128 alone, or in combination with venetoclax. Compared to vehicle treated cells, we observed a significant reduction in cell viability only among $\mathrm{CD} 19+\mathrm{B}$ cells following MLN0128 or SBI-756 treatment (Fig. 6a). The effect of SBI-756 on B cell viability was dose dependent (Fig. S9a). Venetoclax alone greatly reduced viability of $B$ cells, with partial effects on CD4 + and CD $8+T$ cells and natural killer cells as published before. ${ }^{38}$ 

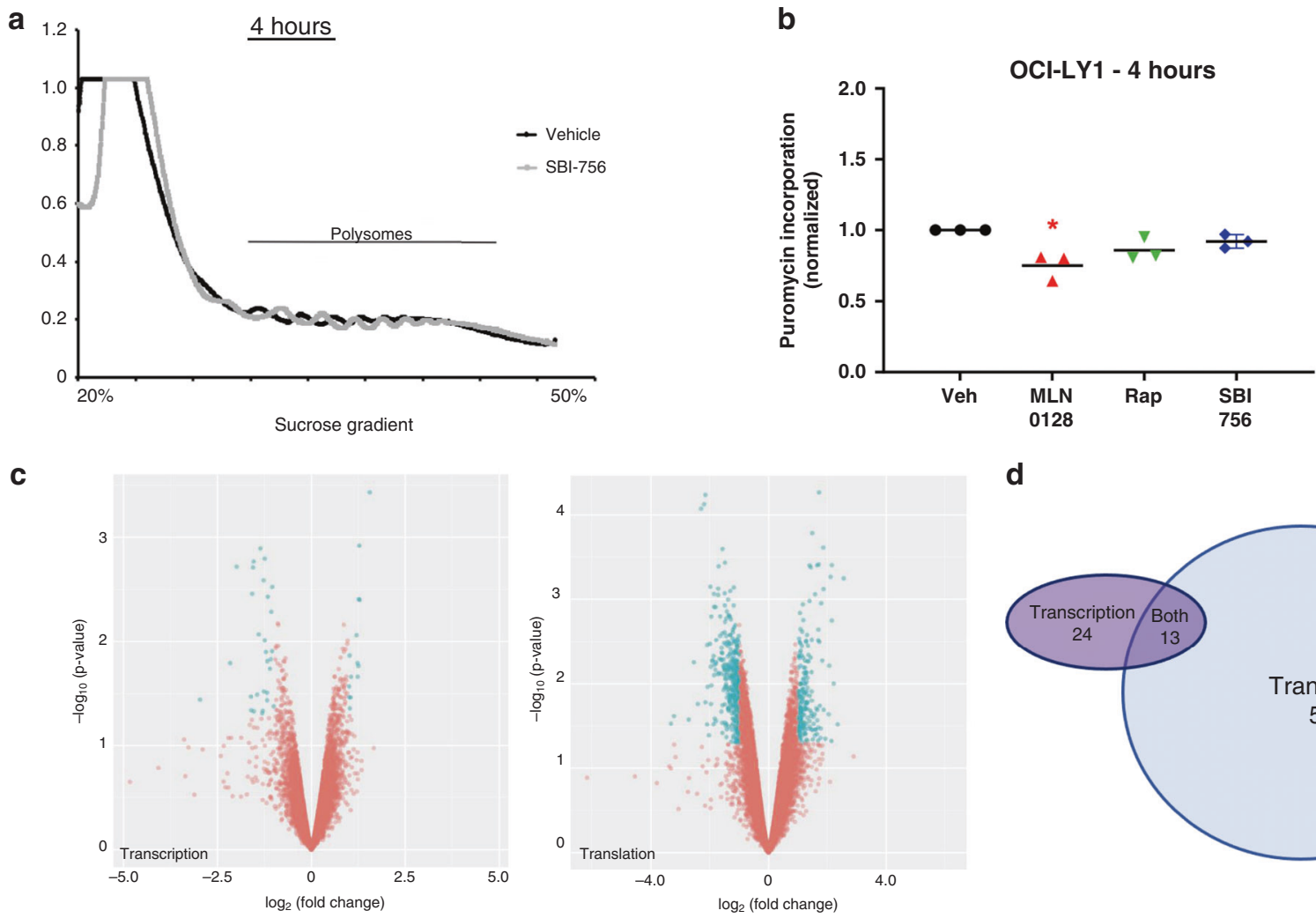

d Top molecular functions
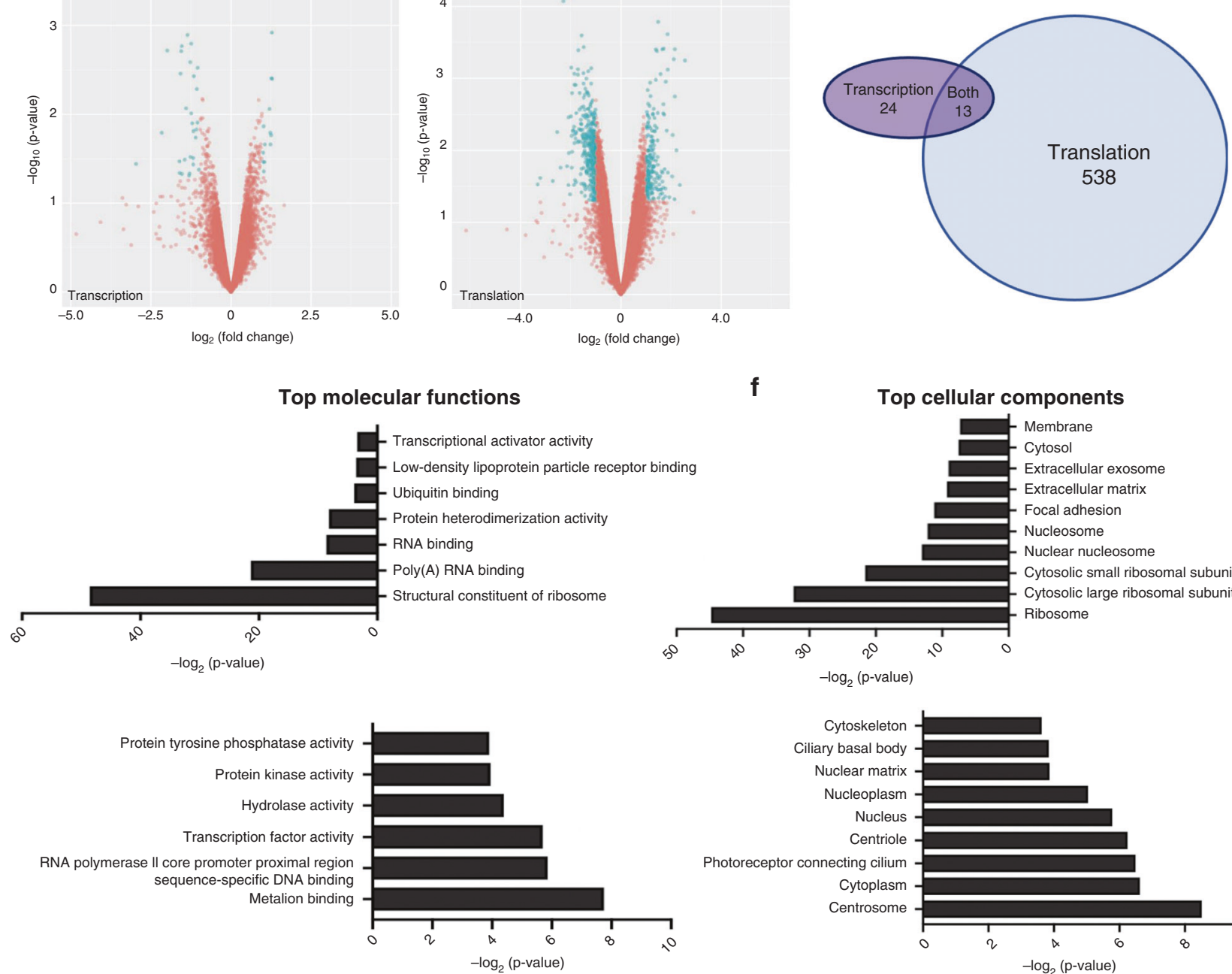

f

Top cellular components
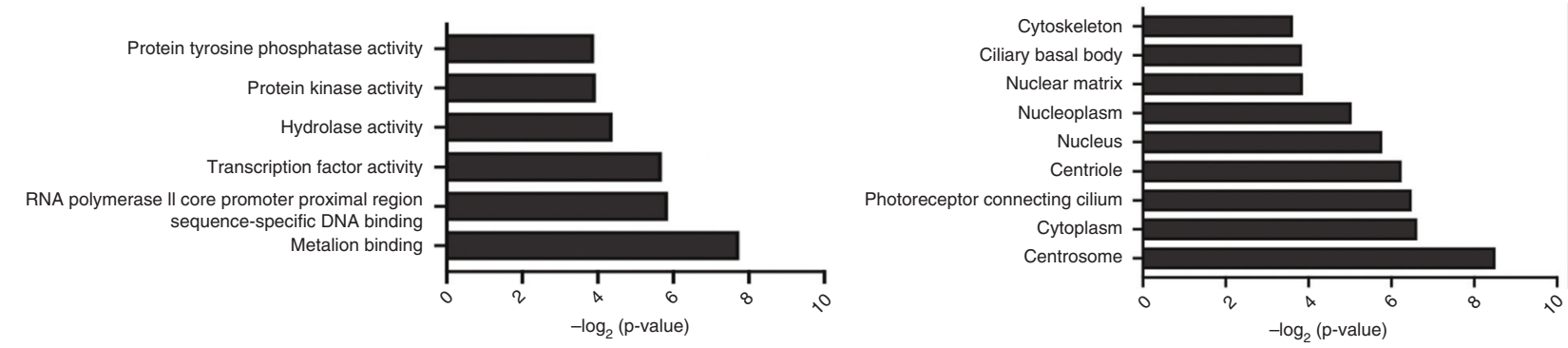

Fig. 4 Selective reduction of mRNA translation following $4 \mathrm{~h}$ SBI-756 treatment. a Polysome traces of OCI-LY1 cells treated with SBI-756 or without (vehicle) for $4 \mathrm{~h}$. Results are representative of three independent samples. b Quantification of puromycin incorporation in OCI-LY1 cells treated with vehicle, MLN0128 $(30 \mathrm{nM})$, rapamycin $(10 \mathrm{nM})$ or SBI-756 $250 \mathrm{nM}$ for $4 \mathrm{~h}$ with addition of puromycin to the media for the last $20 \mathrm{~min}$. c Genome-wide transcription and translation mRNA profiling of 25 million cells with or without SBI-756 treatment. Results are from two independent studies. Total mRNA and purified fractions containing four or more bound ribosomes were sequenced using Illumina HiSeq 4 single read. Volcano plots represent differences in transcription (left) and translation (right). Transcription and translation parameters were $p \leq 0.05$ and $-1.0 \leq \log 2 \geq 1.0$. Blue dots identify mRNAs significantly changed in abundance, and red dots identify mRNAs not significantly changed. Statistical analysis was performed using the limma R package via RIVET (Ernlund AW et al., BMC Genomics 2018). d Venn diagram comparing significant differences in transcription and translation. e The top molecular functions of mRNAs significantly down (top) or upregulated (bottom) in translation. $\mathbf{f}$ The top cellular components of mRNAs significantly down (top) or upregulated (bottom) in translation. 
a

OCI-LY1

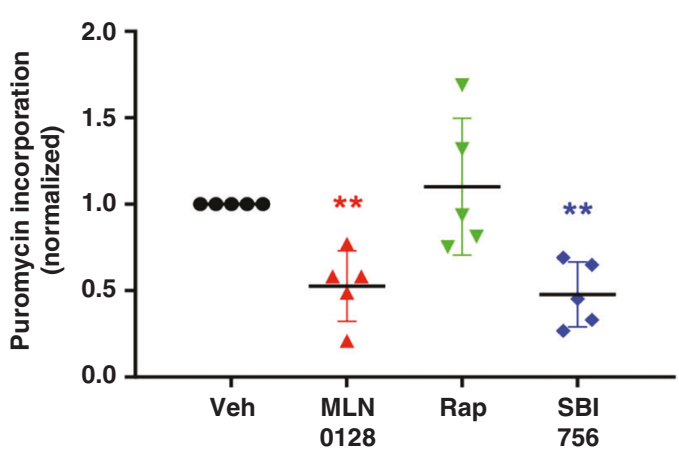

C

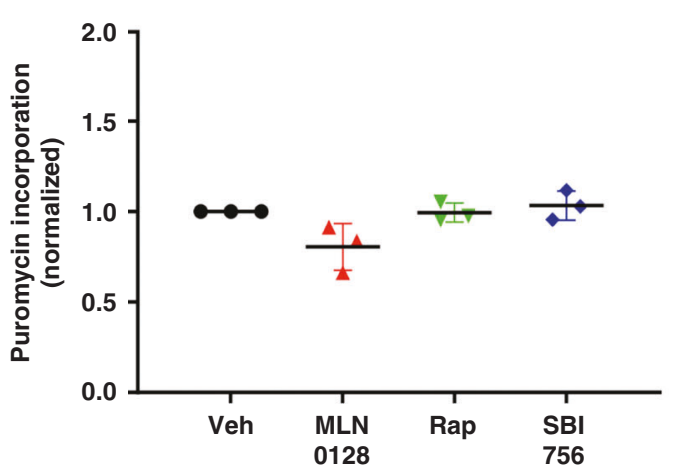

e

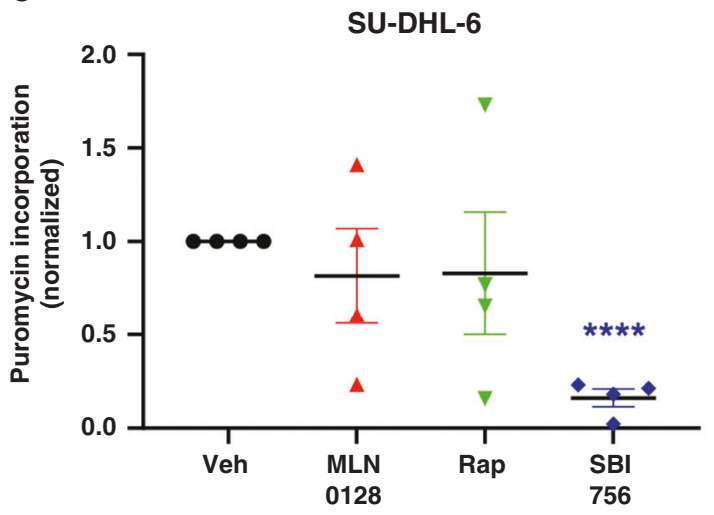

b

OCI-LY1 SBI-756 resistant

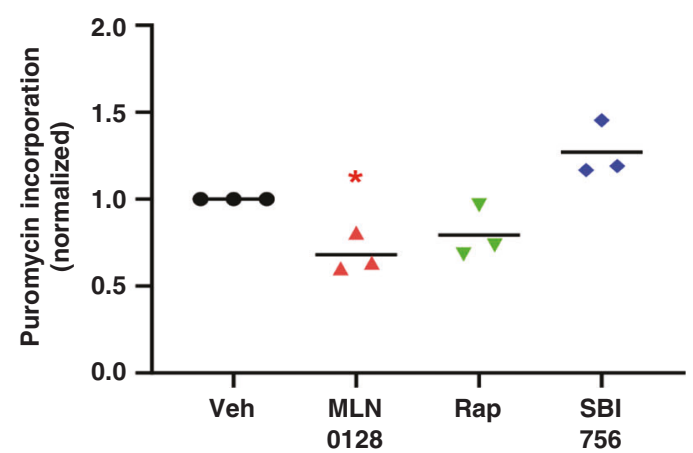

d

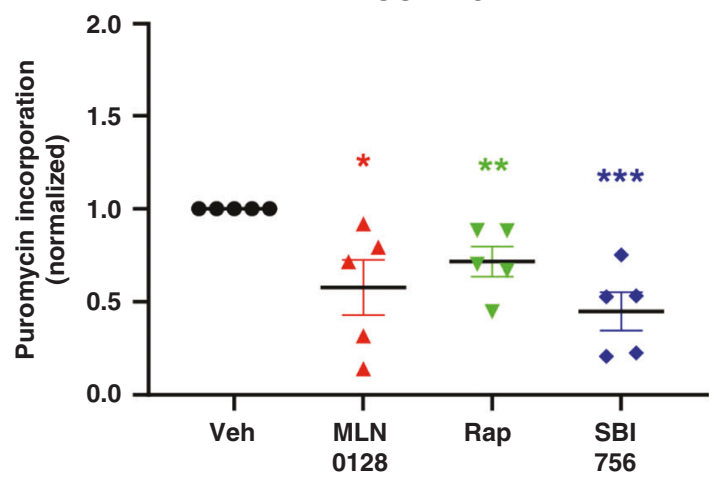

f

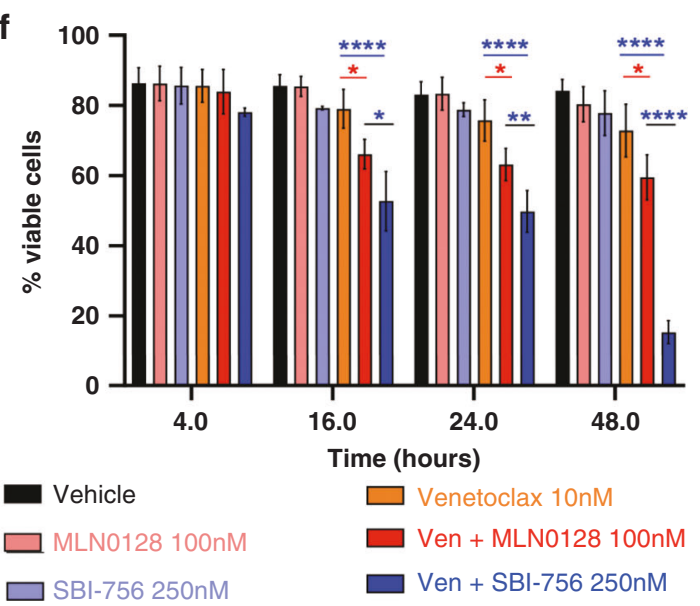

Fig. 5 SBI-756 treatment reduces protein synthesis following $16 \mathbf{h}$ of treatment. We treated cells with vehicle or inhibitors (MLN0128 (30 $\mathrm{nM})$, rapamycin $(10 \mathrm{nM}), \mathrm{SBI}-756250 \mathrm{nM})$ and measured puromycin incorporation after $16 \mathrm{hr}$. a parental OCI-LY1 cells; b OCI-LY1 that were induced to resistance against SBI-756 $(1 \mu \mathrm{M})$; c OCI-LY7; d OCI-LY8; e SU-DHL-6 cells. ${ }^{*} p<0.05,{ }^{* *} p<0.01$. One-sample $t$-test vs. DMSO control. $n=3 . \mathrm{f} \mathrm{OCI}-\mathrm{LY} 1$ cells were treated with venetoclax $10 \mathrm{nM}, \mathrm{MLN} 0128100 \mathrm{nM}, \mathrm{SBI}-756250 \mathrm{nM}$ as single agents or in combination, as indicated. We have assessed their viability after $4,16,24$ or $48 \mathrm{~h}$ of treatment using annexing $\mathrm{V}$ and PI staining and flow cytometry analysis. ${ }^{*} p<0.05$, ${ }^{* *} p<0.01$. One-way ANOVA, compared to venetoclax as single agent.

However, there was no further effect when venetoclax was combined with either MLN0128 or SBI-756 (Fig. 6a). We also tested purified lymphocytes from mice, which are more readily available in quantities needed for correlation of functional and biochemical readouts. Similarly, MLN0128 and SBI-756 were selectively cytotoxic to mouse B cells but not mouse $T$ cells cultured in supportive cytokines (Fig. 6b). The cytotoxic effect of SBI-756 in B cells at $48 \mathrm{~h}$ (Fig. $6 \mathrm{~b}$ ) correlated with suppression of protein synthesis selectively in B cells, measured after 16-h treatment (Fig. 6c).

\section{DISCUSSION}

Venetoclax is a BCL2-specific inhibitor whose use is expanding in hematologic malignancies. ${ }^{20,21}$ However, blood cancer cells frequently engage distinct mechanisms that can maintain survival following BCL2 inhibition. Therefore, responses to venetoclax are broader and more durable when the drug is combined with other agents that promote cell death through distinct mechanisms. ${ }^{39}$ In $\mathrm{DLBCL}$, venetoclax combined with the standard of care (R-CHOP) is more effective than venetoclax monotherapy and components of the CHOP regimen can increase sensitivity to venetoclax 


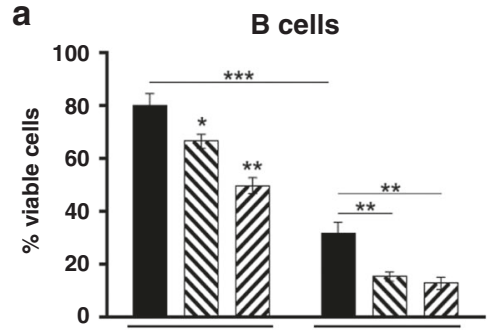

Venetoclax

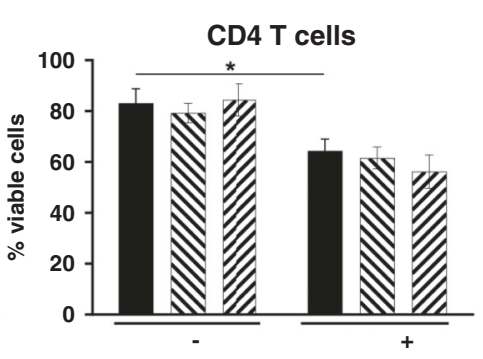

Monocytes

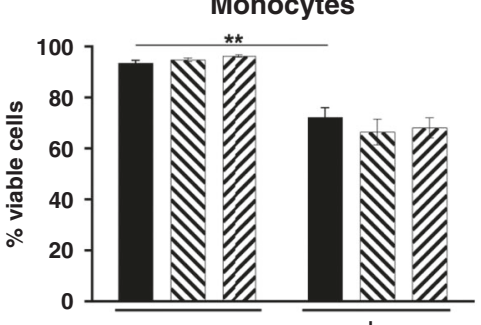

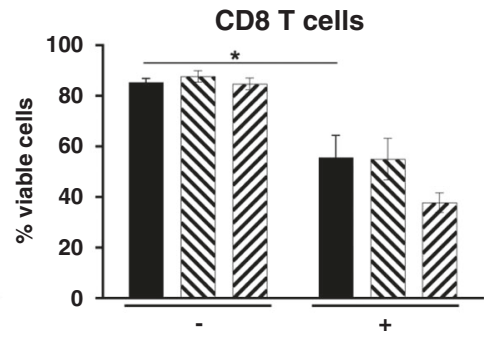

Vehicle

$\triangle \mathrm{MLN} 0128(30 \mathrm{nM})$

$\square \mathrm{SBI}-756$ (250nM)
Venetoclax

NK cells

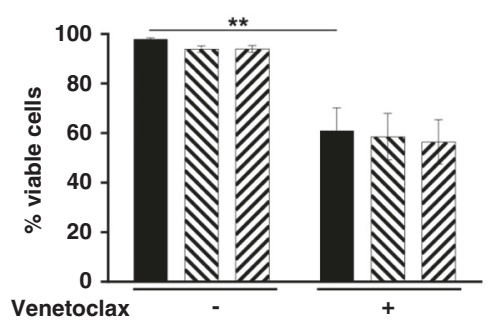

b

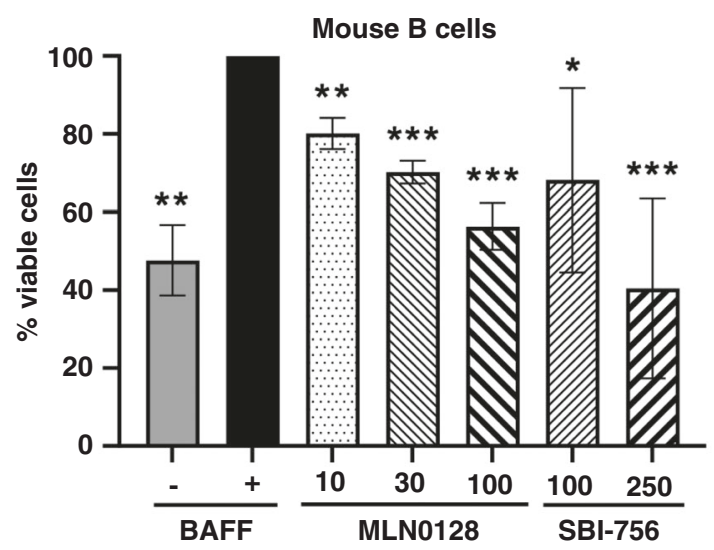

Mouse T cells

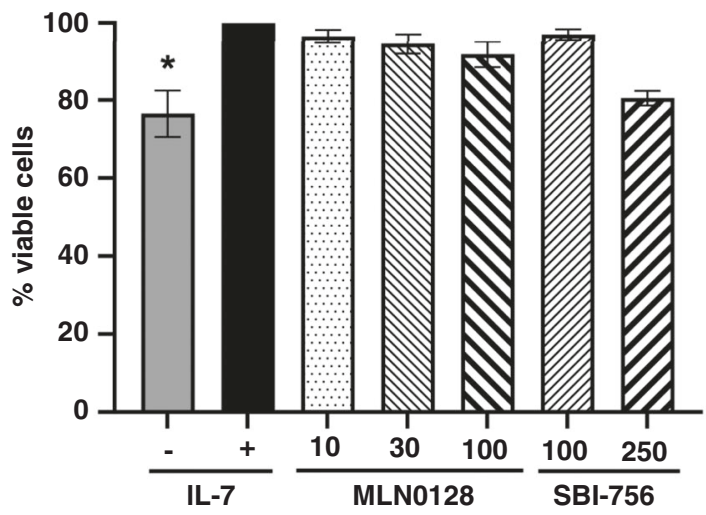

C
B220+

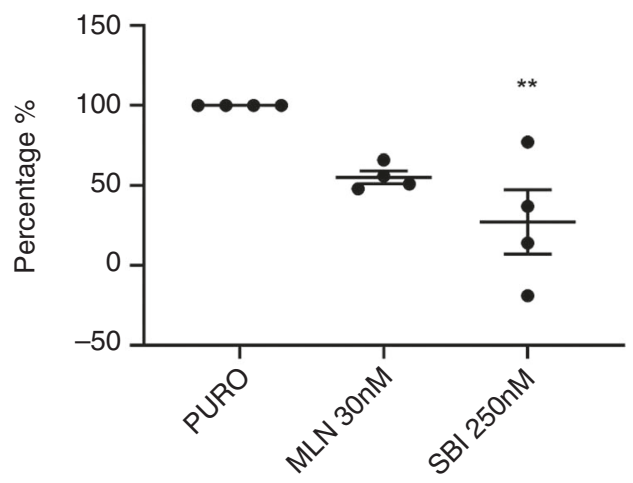

CD3+

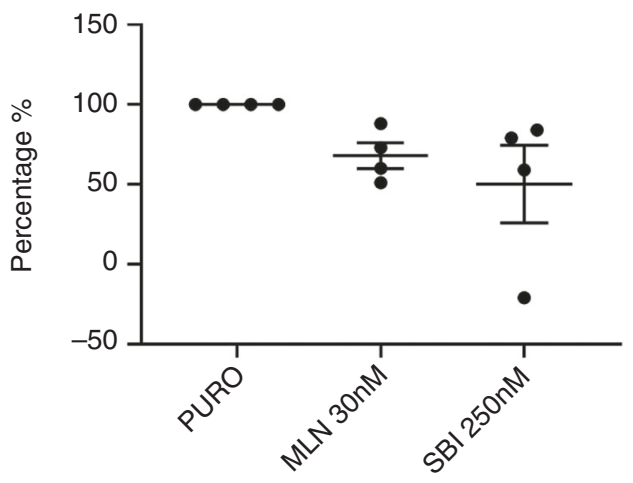

Fig. 6 SBI-756 is not cytotoxic to human CD4 + T cells, CD8 + T cells, NK cells or monocytes. a Peripheral blood mononuclear cells (PBMCs) were obtained from healthy blood donors and were isolated as described previously. ${ }^{38}$ PBMCs (mean $\pm S D, n=3$ ) were cultured for $48 \mathrm{~h}$ with each agent MLN0128 (30 nM), SBI-756 $(250 \mathrm{nM})$ alone or in combination with $100 \mathrm{nM}$ venetoclax. Unpaired $t$-test vs. vehicle (DMSO) control. $n=3$. ${ }^{*} p<0.05,{ }^{* *} p<0.01,{ }^{* *} p<0.005$ vs. DMSO control. Leukocyte subsets were distinguished by surface markers using flow cytometry. b Mouse splenocytes were isolated from C57BL/J mice. We performed B cell or T-cell purification using STEMCELL Mouse B cell or T-cell isolation kit, respectively. Next, we treated the cells as indicated for $48 \mathrm{~h}$ in the presence of cytokines (BAFF or IL-7), and their viability was measured using Annexin V and PI. ${ }^{*} p<0.05,{ }^{* *} p<0.01$. One-sample $t$-test vs. control (control $=\mathrm{B}$ cells $+\mathrm{BAFF} ; \mathrm{T}$ cells $+\mathrm{IL}-7$ ). $n=3$. c Puromycin incorporation in mouse B cells (B220+) and T cell (CD3+) after 16 h of treatment with MLN0128 $30 \mathrm{nM}$ and SBI-756 $250 \mathrm{nM}$. Data are showed as percentage of puromycin incorporation reduction vs vehicle. c vs. DMSO control. $n=4{ }^{* *} p<0.01$. 
in vitro. $^{40,41}$ Incorporation of additional targeted agents has potential to further improve responses. Here, we report experiments showing great potential for sensitisation of $\mathrm{NHL}$ cells to venetoclax via combination with SBI-756, a potent inhibitor of capdependent translation that is active in cells in the $100-500 \mathrm{nM}$ range. SBI-756 synergised with venetoclax to induce apoptosis in $\mathrm{NHL}$ cells while not interfering with mTOR signalling. SBI-756 prevented elF4E:elF4G1 interaction among sensitive cells (OCI-LY1 and OCI-LY8), but not among resistant cells (OCI-LY7 or OCI-LY1 induced to be resistant to SBI-756). After 4-h of treatment, SBI-756 also reduced translation efficiency of mRNAs encoding ribosomal proteins and rRNA processing factors. Consistent with reduced ribosome biogenesis, SBI-756 reduced overall protein synthesis after $16 \mathrm{~h}$ of treatment. Additionally, in DLBCL cell lines lacking 4EBPs (naturally or genetically edited), SBI-756 retained ability to inhibit elF4F formation and sensitise to venetoclax, whereas the TOR-KI compound MLN0128 lacked activity in this setting. SBI-756 synergy with venetoclax in vitro was recapitulated in vivo, with the combination reducing tumour progression that correlated with prevention of elF4E-elF4G1 interaction. Treatment with SBI-756 was tolerable in mice, and the compound selectively reduced survival of B cells in cultures of human PBMCs and murine lymphocytes. Together, these findings urge further investigation of elF4F disruption for sensitisation to venetoclax and possibly other $\mathrm{BH} 3$ mimetics. In this regard, an initial experiment to sensitise DLBCL cell lines to an MCL-1 inhibitor (S63845) using SBI756 (Fig. S9b) yielded a similar response as the venetoclax combination.

$\mathrm{PI} 3 \mathrm{~K} / \mathrm{mTOR}$ signalling pathway activation has been correlated with poor prognosis and resistance to chemotherapy. ${ }^{3}$ Thus, this pathway remains an investigational target for cancer therapeutics, including rapalogs or TOR-Kls such as MLN0128/TAK-228. ${ }^{11}$ However, rapalogs have limited anticancer activity and the therapeutic window for TOR-Kls remains to be established. Targeting individual pathways downstream of mTOR might hold the key to developing better tolerated and more effective anticancer interventions. One process of particular interest is cap-dependent mRNA translation controlled by elF4F. ${ }^{4-6}$ Genetic inhibition of elF4F via inducible expression of the 4E-BP1 mutant sensitised to venetoclax in OCl-LY1 cells, an effect enhanced by the TOR-KI compound MLN0128 that reactivates endogenous 4E-BP1. Our studies of the elF4G-binding compound SBI-756 in human lymphoma cell line models provide proof-of-concept for elF4F disruption by a small molecule at sub- $\mu \mathrm{M}$ concentration. Further studies using pharmacologically optimised inhibitors of elF4G1, or specific knockouts of elF4G1 could clarify the importance of this component in lymphomagenesis or lymphocyte differentiation. In a distinct approach, rocaglate compounds targeting the elF4A helicase can also enhance venetoclax cytotoxicity in lymphoma cells. ${ }^{42}$

In most of the DLBCL and MCL cell lines tested, 48-h treatment with SBI-756 alone had cytotoxic effects as measured by staining with Annexin $\mathrm{V}$ and propidium iodide. In OCI-LY1 and OCI-LY8 cells, this cytotoxic effect was prevented by co-incubation with a pan-caspase inhibitor. However, SBI-756 alone did not cause detectable cleavage of caspase-3 or PARP after $16 \mathrm{~h}$, a time point where these markers were readily induced by venetoclax. It is possible that $\mathrm{SBI}-756$ treatment alone triggers apoptosis at a later time point. Of note, two of the sensitive cell lines (OCI-LY1 and $\mathrm{OCl}$-LY8) express mutant $\mathrm{p} 53{ }^{43}$ suggesting that the mechanism of apoptosis is p53-independent.

Notably, the data suggest that SBI-756 is not cytotoxic to essential cellular mediators of immune function and immunotherapy efficacy ( $T$ cells and NK cells). A potential advantage for tolerability is that SBI-756 treatment (at concentrations of up to $500 \mathrm{nM}$ ) does not interfere with mTOR substrate phosphorylation while disrupting elF4F complex assembly downstream of mTORC1. We did observe that higher concentrations of SBI-756 ( $>500 \mathrm{nM}$ ) do cause inhibition of the mTOR pathway; thus, future efforts should aim to optimise the selectivity of SBI-756 and similar agents. Another advantage of SBI-756 compared to TOR-KI treatment is its ability to suppress cap-dependent translation among cells lacking 4E-BP1, a finding relevant to tumours with reduced ratio of $4 \mathrm{E}-\mathrm{BPs}$ to elF4E. We used cells that naturally lack $4 \mathrm{E}-\mathrm{BP} 1 .^{32}$ or were genome edited to lack $4 \mathrm{E}-\mathrm{BP} 1$ to show that these cells remained sensitive to SBI-756 yet lacked TOR-KI sensitivity. Further experiments are needed to determine whether cells with high elF4E or elF4G1 retain sensitivity to SBI-756. These results suggest that $B$ lineage cells have a unique dependence on the mTORC1/elF4F axis for survival.

Polysome profiling showed that SBI-756 treatment in lymphoma cells alters translation efficiency of 538 genes, transcription of 24 genes, while 13 genes are regulated both transcriptionally and translationally. GO analysis of the translationally downregulated genes identified several groups related to mRNA translation, including structural constituent of the ribosome, ribosomal biogenesis, rRNA binding and translational elongation (Fig. S10). Together, those functions indicate two main effects of SBI-756 treatment: first, direct suppression of translation efficiency of a key subset of cellular mRNAs; second, indirect inhibition of the translation machinery that is needed to sustain protein synthesis. The two effects together (direct and indirect) reprogram mRNA translation in a way that promotes lymphoma cell death and sensitises to BCL2 inhibition. Supporting the correlation of protein synthesis inhibition and cell death, the OCI-LY7 cell line was resistant to SBI-756 cytotoxicity and did not show reduced protein synthesis rates. Moreover, protein synthesis was not reduced among OCl-LY1 cells selected for SBI-756 resistance. Interestingly, the selective cytotoxic effect of SBI-756 on B cells versus T cells correlated with suppression of global protein synthesis.

The polysome profiling dataset does not definitively establish acute effects of SBI-756 on translation efficiency of survival factors, such as ones reported previously to be elF4F-dependent. Western blotting experiments suggested that $\mathrm{SBI}-756$ reduces protein amounts of MCL-1 and survivin, whose expression is known to be sensitive to changes in cap-dependent translation. ${ }^{44}$ This reduction of prosurvival factors may block back-up mechanisms that the cells might use to adjust to BCL2 inhibition. ${ }^{45}$ Another possibility is that the broad reprogramming of translation produces subtle changes that alter the overall balance of prosurvival and proapoptotic proteins over time, tipping the balance towards cell death. ${ }^{4,46}$ Reducing ribosome production using inhibitors of ribosomal DNA transcription likewise promotes lymphoma cell death. ${ }^{47}$

The central role of mRNA translation in hallmarks of cancer has led to many distinct approaches to target regulatory components of the translation machinery. ${ }^{4-6}$ Natural products and synthetic small molecules have been identified with various mechanisms including: (i) interfering with elF4E binding to the $m^{7}$-GTP cap (for example, $4 \mathrm{EGI}-1^{48}$ ); (ii) inhibiting MNK kinases that phosphorylate elF4E (CGP57380; ${ }^{49}$ eFT508 ${ }^{50}$ ); (iii) disrupting the function of elF4A helicase (Silvestrol ${ }^{51}$ and synthetic rocaglates ${ }^{42,52}$ ); (iv) inhibiting translational elongation (homoharringtonine ${ }^{53}$ ). Many of the compounds have low selectivity, weak potency or cell penetrance, poor pharmacological properties or are difficult to synthesise. In the case of $4 \mathrm{EGI}-1$, activity requires $4 \mathrm{E}-\mathrm{BP} 1$ expression. ${ }^{48} \mathrm{SBI}-756$ is a prototype of a novel class that binds to elF4G and disrupts association of this scaffolding protein with elF4E, independent of $4 \mathrm{E}-\mathrm{BP} 1$. Active in cells in the mid-nanomolar range and in mouse models, this compound provides proof of concept for suppressing eIF4F function via blockade of key protein:protein interactions in the complex. Our data indicate that elF4F-disrupting molecules like SBI-756 have great potential to sensitise lymphoma cells to venetoclax. Together with our previous finding that SBI-756 can circumvent resistance to BRAF inhibitors in melanoma, these results support further combination studies of SBI-756 with other targeted agents. 


\section{ACKNOWLEDGEMENTS}

We thank Dr. Selina Chen-Kiang and Dr. Maurizio Di Liberto for providing MCL cell lines, Dr. Bert Semler for providing us with the dual-luciferase reporter construct, Dr. Grant MacGregor for his assistance with performance of dual-luciferase assays and Dr. Adeela Syed for her assistance with microscopy imaging. We also want to thank Dr. Changchun Xiao and his lab for their assistance with polysome fractionation and data analysis, and Dr. Ivan Topisirovic for helpful comments on the manuscript, and Joshua Thao and Madeleine Duong for research contributions.

\section{AUTHOR CONTRIBUTIONS}

L.H., B.W., R.B. and J.S.L. designed and performed experiments, analysed data and wrote the manuscript. S.M., A.F., H.C., N.N. and B.L. performed experiments and analysed data. A.B.P. and M.R.J. conceived the work leading to synthesis of SBI-756, provided materials and interpreted results. R.J.S., Z.A.R. and D.A.F. designed experiments, analysed data and wrote the manuscript.

\section{ADDITIONAL INFORMATION}

Ethics approval and consent to participate Animal studies were approved by the Institutional Animal Care and Use Committee (protocol AUP-18-050) at UC Irvine (accredited by American Association for Accreditation of Laboratory Animal Care). No human subjects research was performed.

Data availability All data supporting the findings of this study are available within the article and its supplementary information files, or from the corresponding author on reasonable request. All RNA-seq data files along with their associated metadata have been deposited in the GEO database under the accession code GSE159906.

Competing interests The authors declare no competing interests.

Funding information This study was supported by: National Institutes of Health grant R01-CA158383 (to D.A.F.), R01-CA202021 (to Z.A.R.), R01-CA178509 (to R.J.S.), American Society for Hematology Bridge grant ASH-5557789 (to D.A.F.), Breast Cancer Research Fund grant BCRF-16-143 (to R.J.S.), Melanoma Research Alliance award 509524 (to Z.A.R.), UC Irvine Chao Family Comprehensive Cancer Center pilot grant from the 2018 Anti-Cancer Challenge (to D.A.F.), and by Cancer Center Support Grant P30-CA062203 to UC Irvine (PI: Van Etten). L.H. and H.C. were supported by National Institutes of Health grant T32 Al 060573. B.W. was supported by a National Institutes of Health grant T32 CA9161.

Supplementary information is available for this paper at https://doi.org/10.1038/ s41416-020-01205-9.

Note This work is published under the standard license to publish agreement. After 12 months the work will become freely available and the license terms will switch to a Creative Commons Attribution 4.0 International (CC BY 4.0).

Publisher's note Springer Nature remains neutral with regard to jurisdictional claims in published maps and institutional affiliations.

\section{REFERENCES}

1. Saxton, R. A. \& Sabatini, D. M. mTOR signaling in growth, metabolism, and disease. Cell 168, 960-976 (2017).

2. Reddy, A., Zhang, J., Davis, N. S., Moffitt, A. B., Love, C. L., Waldrop, A. et al. Genetic and functional drivers of diffuse large b cell lymphoma. Cell 171, 481-494.e15 (2017).

3. Nemes, K., Sebestyén, A., Márk, A., Hajdu, M., Kenessey, I., Sticz, T. et al. Mammalian target of rapamycin (mTOR) activity dependent phospho-protein expression in childhood acute lymphoblastic leukemia (ALL). PLOS ONE 8, e59335 (2013)

4. Bhat, M., Robichaud, N., Hulea, L., Sonenberg, N., Pelletier, J. \& Topisirovic, I. Targeting the translation machinery in cancer. Nat. Rev. Drug Discov. 14, 261-278 (2015).

5. Pelletier, J., Graff, J., Ruggero, D. \& Sonenberg, N. Targeting the elF4F translation initiation complex: a critical nexus for cancer development. Cancer Res. 75, 250-263 (2005).

6. Malka-Mahieu, H., Newman, M., Désaubry, L., Robert, C. \& Vagner, S. Molecular pathways: the elF4F translation initiation complex-new opportunities for cancer treatment. Clin. Cancer Res. 23, 21-25 (2017).

7. Shull, A. Y., Noonepalle, S. K., Awan, F. T., Liu, J., Pei, L., Bollag, R. J. et al. RPPAbased protein profiling reveals elF4G overexpression and 4E-BP1 serine 65 phosphorylation as molecular events that correspond with a pro-survival phenotype in chronic lymphocytic leukemia. Oncotarget 6, 14632-14645 (2015).

8. Janes, M. R., Limon, J. J., So, L., Chen, J., Lim, R. J., Chavez, M. A. et al. Effective and selective targeting of leukemia cells using a TORC1/2 kinase inhibitor. Nat. Med. 16, 205-213 (2010).

9. Yun, S., Vincelette, N. D., Knorr, K. L. B., Almada, L. L., Schneider, P. A., Peterson, K. L. et al. 4EBP1/c-MYC/PUMA and NF-KB/EGR1/BIM pathways underlie cytotoxicity of mTOR dual inhibitors in malignant lymphoid cells. Blood 127, 2711-2722 (2016).

10. Choo, A. Y., Yoon, S.-O., Kim, S. G., Roux, P. P. \& Blenis, J. Rapamycin differentially inhibits S6Ks and 4E-BP1 to mediate cell-type-specific repression of mRNA translation. Proc. Natl Acad. Sci. USA 105, 17414-17419 (2008).

11. Lee, J.-H. S., Vo, T.-T. \& Fruman, D. A. Targeting mTOR for the treatment of B cell malignancies. Br. J. Clin. Pharmacol. 82, 1213-1228 (2016).

12. Benjamin, D., Colombi, M., Moroni, C. \& Hall, M. N. Rapamycin passes the torch: a new generation of mTOR inhibitors. Nat. Rev. Drug Discov. 10, 868-880 (2011).

13. Janes, M. R., Vu, C., Mallya, S., Shieh, M. P., Limon, J. J., Li, L. S. et al. Efficacy of the investigational mTOR kinase inhibitor MLN0128/INK128 in models of B-cell acute lymphoblastic leukemia. Leukemia 27, 586-594 (2016).

14. Burris, H. A., Kurkjian, C. D., Hart, L., Pant, S., Murphy, P. B., Jones, S. F. et al. TAK228 (formerly MLN0128), an investigational dual TORC1/2 inhibitor plus paclitaxel, with/without trastuzumab, in patients with advanced solid malignancies. Cancer Chemother. Pharmacol. 80, 261-273 (2017).

15. Rodrik-Outmezguine, V. S., Chandarlapaty, S., Pagano, N. C., Poulikakos, P. I., Scaltriti, M., Moskatel, E. et al. mTOR kinase inhibition causes feedbackdependent biphasic regulation of AKT signaling. Cancer Discov. 1, 248-259 (2011).

16. Grabiner, B. C., Nardi, V., Birsoy, K., Possemato, R., Shen, K., Sinha, S. et al. A diverse array of cancer-associated MTOR mutations are hyperactivating and can predict rapamycin sensitivity. Cancer Discov. 4, 554-563 (2014).

17. Truitt, M. L., Conn, C. S., Shi, Z., Pang, X., Tokuyasu, T., Coady, A. M. et al. Differential requirements for elF4E dose in normal development and cancer. Cell 162, 59-71 (2015).

18. Mills, J. R., Hippo, Y., Robert, F., Chen, S. M. H., Malina, A., Lin, C.-J. et al. mTORC1 promotes survival through translational control of Mcl-1. Proc. Natl Acad. Sci. USA 105, 10853-10858 (2008).

19. Feng, Y., Pinkerton, A. B., Hulea, L., Zhang, T., Davies, M. A., Grotegut, S. et al. SBI0640756 attenuates the growth of clinically unresponsive melanomas by disrupting the elF4F translation initiation complex. Cancer Res. 75, 5211-5218 (2015).

20. Merino, D., Kelly, G. L., Lessene, G., Wei, A. H., Roberts, A. W. \& Strasser, A. BH3mimetic drugs: blazing the trail for new cancer medicines. Cancer Cell 34, 879-891 (2018).

21. Leverson, J. D., Sampath, D., Souers, A. J., Rosenberg, S. H., Fairbrother, W. J., Amiot, M. et al. Found in translation: how preclinical research is guiding the clinical development of the BCL2-selective inhibitor venetoclax. Cancer Discov. 7, 1376-1393 (2017)

22. Roberts, A. W., Davids, M. S., Pagel, J. M., Kahl, B. S., Puvvada, S. D., Gerecitano, J. F. et al. Targeting BCL2 with venetoclax in relapsed chronic lymphocytic leukemia. N. Engl. J. Med. 374, 311-322 (2016).

23. Seymour, J. F., Kipps, T. J., Eichhorst, B., Hillmen, P., D'Rozario, J., Assouline, S. et al. Venetoclax-rituximab in relapsed or refractory chronic lymphocytic leukemia. $N$. Engl. J. Med. 378, 1107-1120 (2018).

24. DiNardo, C. D., Pratz, K., Pullarkat, V., Jonas, B. A., Arellano, M., Becker, P. S. et al. Venetoclax combined with decitabine or azacitidine in treatment-naive, elderly patients with acute myeloid leukemia. Blood 133, 7-17 (2019).

25. Davids, M. S., Roberts, A. W., Seymour, J. F., Pagel, J. M., Kahl, B. S., Wierda, W. G. et al. Phase I first-in-human study of venetoclax in patients with relapsed or refractory non-hodgkin lymphoma. J. Clin. Oncol. 35, 826-833 (2017).

26. Chiu, H., Jackson, L. V., Oh, K. I., Mai, A., Ronai, Z. A., Ruggero, D. et al. The mTORC1/4E-BP/elF4E axis promotes antibody class switching in B lymphocytes. J. Immunol. 202, 579-590 (2019).

27. Boussemart, L., Malka-Mahieu, H., Girault, I., Allard, D., Hemmingsson, O., Tomasic, G. et al. elF4F is a nexus of resistance to anti-BRAF and anti-MEK cancer therapies. Nature 513, 105-109 (2014).

28. Ernlund, A. W., Schneider, R. J. \& Ruggles, K. V. RIVET: comprehensive graphic user interface for analysis and exploration of genome-wide translatomics data. BMC Genomics 19, 809 (2018).

29. Choudhary, G. S., Al-Harbi, S., Mazumder, S., Hill, B. T., Smith, M. R., Bodo, J. et al. MCL-1 and BCL-xL-dependent resistance to the BCL-2 inhibitor ABT-199 can be overcome by preventing PI3K/AKT/mTOR activation in lymphoid malignancies. Cell Death Dis. 6, e1593 (2015)

30. So, L., Lee, J., Palafox, M., Mallya, S., Woxland, C. G., Arguello, M. et al. The 4E-BPelF4E axis promotes rapamycin-sensitive growth and proliferation in lymphocytes. Sci. Signal. 9, ra57 (2016). 
31. Chou, T.-C. Drug combination studies and their synergy quantification using the Chou-Talalay method. Cancer Res. 70, 440-446 (2010).

32. Mallya, S., Fitch, B. A., Lee, J. S., So, L., Janes, M. R. \& Fruman, D. A. Resistance to mTOR kinase inhibitors in lymphoma cells lacking 4EBP1. PLoS ONE 9, e88865 (2014).

33. Martineau, Y., Azar, R., Müller, D., Lasfargues, C., El Khawand, S., Anesia, R. et al. Pancreatic tumours escape from translational control through 4E-BP1 loss. Oncogene 33, 1367-1374 (2013).

34. Li, B. D., Liu, L., Dawson, M. \& De Benedetti, A. Overexpression of eukaryotic initiation factor 4E (elF4E) in breast carcinoma. Cancer 79, 2385-2390 (1997).

35. Xu, T., Zong, Y., Peng, L., Kong, S., Zhou, M., Zou, J. et al. Overexpression of elF4E in colorectal cancer patients is associated with liver metastasis. Onco Targets Ther. 9, 815-822 (2016).

36. Alain, T., Morita, M., Fonseca, B. D., Yanagiya, A., Siddiqui, N., Bhat, M. et al. elF4E/ $4 \mathrm{E}-\mathrm{BP}$ ratio predicts the efficacy of mTOR targeted therapies. Cancer Res. 72 6468-6476 (2012).

37. Gandin, V., Masvidal, L., Hulea, L., Gravel, S.-P., Cargnello, M., McLaughlan, S. et al. nanoCAGE reveals $5^{\prime}$ UTR features that define specific modes of translation of functionally related MTOR-sensitive mRNAs. Genome Res. 26, 636-648 (2016).

38. Lee, J. S., Roberts, A., Juarez, D., Vo T.-T. T., Bhatt, S., Herzog, L. et al. Statins enhance efficacy of venetoclax in blood cancers. Sci. Transl. Med. 10, eaaq1240 (2018).

39. Bose, P., Gandhi, V. \& Konopleva, M. Pathways and mechanisms of venetoclax resistance. Leuk. Lymphoma 58, 1-17 (2017).

40. Zelenetz, A. D., Salles, G., Mason, K. D., Casulo, C., Le Gouill, S., Sehn, L. H. et al. Venetoclax plus R- or G-CHOP in non-Hodgkin lymphoma: results from the CAVALLI phase 1b trial. Blood 33, 1964-1976 (2019).

41. de Jong, M. R. W., Langendonk, M., Reitsma, B., Nijland, M., van den Berg, A Ammatuna, E. et al. Heterogeneous pattern of dependence on anti-apoptotic BCL-2 family proteins upon CHOP treatment in diffuse large B-cell lymphoma. Int. J. Mol. Sci. 20, 6036 (2019).

42. Zhang, X., Bi, C., Lu, T., Zhang, W., Yue, T., Wang, C. et al. Targeting translation initiation by synthetic rocaglates for treating MYC-driven lymphomas. Leukemia 34, 138-150 (2019).

43. Houldsworth, J., Petlakh, M., Olshen, A. B. \& Chaganti, R. S. K. Pathway activation in large B-cell non-Hodgkin lymphoma cell lines by doxorubicin reveals prognostic markers of in vivo response. Leuk. Lymphoma 49, 2170-2180 (2008).
44. Willimott, S., Beck, D., Ahearne, M. J., Adams, V. C. \& Wagner, S. D. Cap-translation inhibitor, 4EGI-1, restores sensitivity to ABT-737 apoptosis through capdependent and -independent mechanisms in chronic lymphocytic leukemia. Clin. Cancer Res. 19, 3212-3223 (2013).

45. Huang, S., Jiang, C., Guo, H., Wang, J., Liu, Y., Li, C. et al. Resistance mechanisms underlying venetoclax resistance in mantle cell lymphoma. Blood 130, (Supplement 1):2749 (2017).

46. Bywater, M. J., Poortinga, G., Sanij, E., Hein, N., Peck, A., Cullinane, C. et al. Inhibition of RNA polymerase I as a therapeutic strategy to promote cancer-specific activation of p53. Cancer Cell. 22, 51-65 (2012).

47. Devlin, J. R., Hannan, K. M., Hein, N., Cullinane, C., Kusnadi, E., Ng, P. Y. et al. Combination therapy targeting ribosome biogenesis and mRNA translation synergistically extends survival in MYC-driven lymphoma. Cancer Discov. 6, 59-70 (2016).

48. Moerke, N. J., Aktas, H., Chen, H., Cantel, S., Reibarkh, M. Y., Fahmy, A. et al. Smallmolecule inhibition of the interaction between the translation initiation factors elF4E and elF4G. Cell 128, 257-267 (2017).

49. Lim, S., Saw, T. Y., Zhang, M., Janes, M. R., Nacro, K., Hill, J. et al. Targeting of the MNK-eIF4E axis in blast crisis chronic myeloid leukemia inhibits leukemia stem cell function. Proc. Natl Acad. Sci. USA 110, E2298-E2307 (2013).

50. Reich, S. H., Sprengeler, P. A., Chiang, G. G., Appleman, J. R., Chen, J., Clarine, J. et al. Structure-based design of pyridone-aminal eFT508 targeting dysregulated translation by selective mitogen-activated protein kinase interacting kinases 1 and 2 (MNK1/2) inhibition. J. Med. Chem. 61, 3516-3540 (2018).

51. Bordeleau, M.-E., Robert, F., Gerard, B., Lindqvist, L., Chen, S. M. H., Wendel, H.-G. et al. Therapeutic suppression of translation initiation modulates chemosensitivity in a mouse lymphoma model. J. Clin. Invest. 118, 2651-2660 (2008).

52. Chu, J., Zhang, W., Cencic, R., Devine, W. G., Beglov, D., Henkel, T. et al. Amidinorocaglates: a potent class of elF4A inhibitors. Cell Chem. Biol. 26, 1586-1593.e3 (2019).

53. Klanova, M., Andera, L., Brazina, J., Svadlenka, J., Benesova, S., Soukup, J. et al. Targeting of BCL2 family proteins with ABT-199 and homoharringtonine reveals BCL2- and MCL1-dependent subgroups of diffuse large B-cell lymphoma. Clin. Cancer Res. 22, 1138-1149 (2016). 